\title{
Inattention and Inertia in Household Finance: Evidence from the Danish Mortgage Market
}

\section{Citation}

Andersen, Steffen, John Y. Campbell, Kasper Meisner Nielsen, and Tarun Ramadorai. "Inattention and Inertia in Household Finance: Evidence from the Danish Mortgage Market." SSRN Electronic Journal. doi:10.2139/ssrn.2463575.

\section{Published Version}

doi: $10.2139 /$ ssrn. 2463575

\section{Permanent link}

http://nrs.harvard.edu/urn-3:HUL.InstRepos:17492179

\section{Terms of Use}

This article was downloaded from Harvard University's DASH repository, and is made available under the terms and conditions applicable to Open Access Policy Articles, as set forth at http:// nrs.harvard.edu/urn-3:HUL.InstRepos:dash.current.terms-of-use\#OAP

\section{Share Your Story}

The Harvard community has made this article openly available.

Please share how this access benefits you. Submit a story.

\section{Accessibility}




\title{
Inattention and Inertia in Household Finance: Evidence from the Danish Mortgage Market
}

\author{
Steffen Andersen, John Y. Campbell, Kasper Meisner Nielsen, \\ and Tarun Ramadorai ${ }^{1}$
}

First draft: July 2014

This version: June 2015

\footnotetext{
${ }^{1}$ Andersen: Department of Finance, Copenhagen Business School, Porcelaenshaven 16A, DK-2000 Frederiksberg, Denmark, Email: sa.eco@cbs.dk. Campbell: Department of Economics, Littauer Center, Harvard University, Cambridge MA 02138, USA, and NBER. Email: john_campbell@harvard.edu. Nielsen: Hong Kong University of Science and Technology, Clear Water Bay, Hong Kong SAR, China. Email: nielsen@ust.hk. Ramadorai: Saïd Business School, Oxford-Man Institute of Quantitative Finance, University of Oxford, Park End Street, Oxford OX1 1HP, UK, and CEPR. Email: tarun.ramadorai@sbs.ox.ac.uk. We thank the Sloan Foundation for financial support. We are grateful to the Association of Danish Mortgage Banks (ADMB) for providing data and facilitating dialogue with the individual mortgage banks, and to senior economists Bettina Sand and Kaare Christensen at the ADMB for providing us with valuable institutional details. We thank Sumit Agarwal, Joao Cocco, Xavier Gabaix, David Laibson, Tomasz Piskorski, Tano Santos, Antoinette Schoar, Amit Seru, Susan Woodward, Vincent Yao, and seminar participants at the Board of Governors of the Federal Reserve/GFLEC Financial Literacy Seminar at George Washington University, the NBER Summer Institute Household Finance Meeting, the Riksbank-EABCN conference on Inequality and Macroeconomics, the American Economic Association 2015 Meeting, the Real Estate Seminar at UC Berkeley, the Federal Reserve Bank of New York, Copenhagen Business School, Columbia Business School, the May 2015 Mortgage Contract Design Conference, the NUS-IRES Real Estate Symposium, and the Booth School of Business at the University of Chicago for many useful comments, and Josh Abel for excellent and dedicated research assistance.
} 


\begin{abstract}
This paper studies inattention to mortgage refinancing incentives among Danish households. Danish data are particularly suitable for this purpose because there are minimal barriers to refinancing, yet many borrowers fail to refinance optimally, and the characteristics of these borrowers can be accurately measured. The paper estimates a mixture model of household refinancing types in which household characteristics affect both inattention (a low proportion of rational refinancers) and residual inertia (a low probability that fully inattentive households refinance). Many characteristics move inattention and inertia in the same direction, implying a positive cross-sectional correlation of 0.62 between these two household attributes. Younger, better educated, and higher-income households have less inertia and less inattention. Financial wealth and housing wealth have opposite effects, with the least inertia and inattention among households whose housing wealth is high relative to their financial wealth. There is suggestive evidence of persistent unobserved heterogeneity in attention.
\end{abstract}




\section{Introduction}

A pervasive finding in studies of household financial decisionmaking is that households respond slowly to changing financial incentives. Inaction is common, even in circumstances where market conditions are changing continuously, and actions often occur long after the incentive to take them has first arisen. Well known examples include participation, saving, and asset allocation decisions in retirement savings plans and portfolio rebalancing in response to fluctuations in risky asset prices. $^{2}$ This paper studies mortgage refinancing, a particularly important decision given the size of mortgages relative to households' income and their other assets and liabilities.

A standard explanation for inaction is that action incurs fixed costs, so that it should only be undertaken when the benefits are sufficiently large. (S,s) models of optimal inaction in the presence of fixed costs have been a staple of the economics literature since the 1950s. More recently, the literature has considered costs of observing and processing information that can potentially explain why households are inattentive to incentives, failing to take action even outside the standard $(\mathrm{S}, \mathrm{s})$ inaction range. ${ }^{3}$

In this paper we estimate an empirical model of household inattention to mortgage refinancing incentives. The model has several important ingredients. First, it incorporates a formula for the inaction range given fixed costs of refinancing, due to Agarwal, Driscoll, and Laibson (ADL 2013). Second, we use a standard econometric formulation of stochastic errors in discrete choice that effectively smooths the ADL refinancing threshold, implying a rapid but not discontinuous increase in refinancing probability around the threshold. Third,

\footnotetext{
${ }^{2}$ See for example Agnew, Balduzzi, and Sunden (2003), Choi, Laibson, Madrian, and Metrick (2002, 2004), and Madrian and Shea (2001) on retirement savings plans, and Bilias, Georgarakos, and Haliassos (2010), Brunnermeier and Nagel (2008), and Calvet, Campbell, and Sodini (2009a) on portfolio rebalancing.

${ }^{3}$ Observation costs are modeled by Duffie and Sun (1990), Gabaix and Laibson (2002), Reis (2006), and Abel, Eberly, and Panageas (2007) among others. Sims (2003) uses the concept of entropy to model information processing costs, an approach followed by Moscarini (2004) and Woodford (2009) among others. Optimal behavior is hard to characterize in the presence of both standard fixed costs and information processing costs, since it typically involves a mix of time-dependent and state-dependent actions (Alvarez, Lippi, and Paciello 2011, Abel, Eberly, and Panageas 2013). Alvarez, Guiso, and Lippi (2012) make some progress using data in which households' observations of financial conditions are directly measured.
} 
we specify household behavior as a weighted average or mixture of fully attentive refinancing and completely inattentive refinancing, thereby allowing continuous variation in household inattention. 4 We call fully attentive refinancers "levelheads", and following mortgage industry slang and Deng and Quigley (2012), we call completely inattentive refinancers "woodheads". Fourth, the model allows inattentive refinancing to take place at an arbitrary base rate independent of incentives. A low level of this base refinancing rate represents inertia, or household reluctance to take action, for an inattentive woodhead household. Finally, the model allows both inattention and inertia to vary cross-sectionally with household and mortgage characteristics.

Almost all previous research on mortgage refinancing has studied US data. Mortgage prepayment behavior, and prepayment risk created by random time-variation in prepayment rates, were the main preoccupations of a large literature on the pricing and hedging of US mortgage-backed securities in the years before the global financial crisis of the late 2000s. ${ }^{5}$ However US data are problematic in two respects. First, the US mortgage system constrains refinancing when households have negative home equity or impaired credit scores, and it can be very difficult to fully control for these constraints. ${ }^{6}$ Second, it is challenging to measure borrower characteristics in the US system since these are reported only at the time of a mortgage application through the form required by the Home Mortgage Disclosure Act (HMDA), and hence one cannot directly compare the characteristics of refinancers and nonrefinancers at a point in time. An alternative is to use survey data, but these can be

\footnotetext{
${ }^{4}$ Mixture models have a long history in statistics since Pearson (1894). A recent survey is presented in McLachlan and Peel (2000). Two current applications where mixture models are used to uncover decision rules are El-Gamal and Grether (1995) for Bayesian updating behavior, and Harrison and Rutström (2009) for models of decision-making under risk.

${ }^{5}$ See for example Schwartz and Torous (1989), McConnell and Singh (1994), Stanton (1995), Deng, Quigley, and Van Order (2000), Bennett, Peach, and Peristiani (2001), and Gabaix, Krishnamurthy, and Vigneron (2007). Two important exceptions to the US focus of the prepayment literature are Miles (2004) and Bajo, Barbi, and Bartoli (2014), which study the UK and Italy respectively.

${ }^{6}$ Johnson, Meier, and Toubia (2015) surmount this difficulty by studying pre-approved refinancing offers from a large US financial institution. Earlier attempts to control for constraints include Archer, Ling, and McGill (1996), Caplin, Freeman, and Tracy (1997), Campbell (2006), Schwartz (2006), and Keys, Pope, and Pope (2014). In the aftermath of the global financial crisis, the US government has tried to relax refinancing constraints through the Home Affordable Refinance Program (HARP), but the effectiveness of this program remains an outstanding research question (Zandi and deRitis 2011, Tracy and Wright 2012, Zhu 2012).
} 
extremely noisy. ${ }^{7}$

We instead study a comprehensive administrative dataset on recent refinancing decisions in Denmark. The Danish mortgage system is similar to the US system in that long-term fixed-rate mortgages are common and can be refinanced without penalties related to the level of interest rates. However the Danish context has two special advantages that make it ideal for measuring household inattention. First, Danish households are free to refinance whenever they choose to do so, even if their home equity is negative or their credit standing has deteriorated, provided that they do not increase their outstanding principal balance. This allows us to study household inattention and inertia without having to control for the additional constraints that limit refinancing in the US. Second, the Danish statistical system provides us with accurate administrative data on household demographic and financial characteristics, for all mortgage borrowers including both refinancers and non-refinancers. This allows us to characterize in great detail the cross-sectional determinants of inattention and inertia.

Our main results are as follows. First, errors of omission, where households fail to refinance despite incentives greater than the ADL threshold for rational refinancing, are much more common in the Danish data than errors of commission, where households refinance too early at savings less than the ADL threshold. ${ }^{8}$ Along the observed path for Danish interest rates, these errors of omission often involve substantial costs for households. Second, inattention varies with numerous household demographic and financial characteristics. It is lower for young households with at least a high-school education, and decreases with income and housing wealth but increases with financial wealth. Third, the residual inertia of inattentive households is not constant but positively correlated with inattention in the crosssection. Demographic characteristics that predict less attention to incentives also typically

\footnotetext{
${ }^{7}$ See LaCour-Little (1999), Campbell (2006), Schwartz (2006), and Agarwal, Rosen, and Yao (2012) for attempts to measure refinancer characteristics using US data. Schwartz (2006) documents the poor data quality of the American Housing Survey.

${ }^{8}$ We borrow this terminology from Agarwal, Rosen, and Yao (2012), who report similar results in US data but can only study delays in refinancing among refinancers, since they do not have data on people who fail to refinance altogether. Keys, Pope, and Pope (2014) use data on outstanding mortgages to circumvent this problem, but give up the ability to measure borrower characteristics contemporaneously.
} 
predict a lower base rate of refinancing. Fourth, there is suggestive evidence that attention is a persistent household characteristic, not fully captured by observed demographics, so that the history of refinancing incentives for a cohort of mortgages affects the attention level of those mortgages that remain in the pool without having been refinanced.

Our work fits into a broader literature on the difficulties households have in managing their mortgage borrowing. Campbell and Cocco (2003, 2015) specify models of optimal choice between FRMs and ARMs, and optimal prepayment and default decisions, showing how challenging it is to make these decisions correctly. Chen, Michaux, and Roussanov (2013) similarly study decisions to extract home equity through cash-out refinancing, while Bhutta and Keys (2013) and Khandani, Lo, and Merton (2013) argue that households used cash-out refinancing to borrow too aggressively during the housing boom of the early 2000s. Bucks and Pence (2008) provide direct survey evidence that ARM borrowers are unaware of the exact terms of their mortgages, specifically the range of possible variation in their mortgage rates. Woodward and Hall (2010, 2012) study the fees that borrowers pay at mortgage origination, arguing that insufficient shopping effort leads to excessive fees.

The organization of the paper is as follows. Section 2 explains the Danish mortgage system and household data. Section 3 presents our mixture model of household refinancing types. Section 4 estimates the model empirically, and section 5 concludes. An online appendix (Andersen, Campbell, Nielsen, and Ramadorai 2015) provides supporting details.

\section{The Danish Mortgage System and Household Data}

\subsection{The Danish mortgage system}

The Danish mortgage system has attracted considerable attention internationally because, while similar to the US system in offering long-term fixed-rate mortgages without prepayment penalties, it has numerous design features that differ from the US model and have performed 
well in recent years (Campbell 2013, Gyntelberg et al. 2012, Lea 2011). In this section we briefly review the funding of Danish mortgages and the rules governing refinancing. (The online appendix provides a few additional details on the Danish system.)

\section{A. Mortgage funding}

Danish mortgages, like those in some other continental European countries, are funded using covered bonds: obligations of mortgage lenders that are collateralized by pools of mortgages. The Danish market for covered mortgage bonds is the largest in the world, both in absolute terms and relative to the size of the economy. The market value of all Danish outstanding mortgage bonds in 2012 was DKK 2,456bn (EUR 330bn), exceeding the Danish GDP of DKK 1,826bn (EUR 245bn). ${ }^{9}$

Mortgages in Denmark are issued by mortgage banks that act as intermediaries between investors and borrowers. Investors buy mortgage bonds issued by the mortgage bank, and borrowers take out mortgages from the bank. All lending is secured and mortgage banks have no influence (apart from the initial screening) on the yield on the loans granted, which is entirely determined by the market. There is no direct link between the borrower and the investor. Instead investors buy bonds that are backed by a pool of borrowers. If a borrower defaults, the mortgage bank must replace the defaulted mortgage in the pool that backs the mortgage bond. This ensures that investors are unaffected by defaults in their borrower pool so long as the mortgage bank remains solvent.

In the event of a borrower default, the mortgage bank can enforce its contractual right by triggering a forced sale (foreclosure) which is carried through by the enforcement court, part of the court system in Denmark. To the extent that the proceeds of a forced sale are insufficient to pay off mortgages, uncovered claims are converted to personal claims held by the mortgage bank against the borrower. In other words Danish mortgages (like those elsewhere in Europe) have personal recourse against borrowers.

\footnotetext{
${ }^{9}$ Data from the European Covered Bonds Council show that the largest covered mortgage bond markets in 2013 were, in order, Denmark, Spain, Sweden, France, and Germany. Germany had the largest overall covered bond market, followed by Denmark and Spain.
} 
These features of the Danish system, together with strict regulation of mortgage loanto-value ratios, mortgage maturities, and housing valuation procedures, have led to unusual stability of mortgage funding. There have been no mortgage bond defaults and only a few cases of delayed payments to mortgage bond investors, the last of which occurred in the 1930s.

Danish mortgage bonds are currently issued by seven mortgage banks. While mortgages on various types of real properties are eligible as collateral for mortgage bonds, mortgages on residential properties dominate most collateral pools. Owner-occupied housing makes up around $60 \%$ of mortgage pools, followed by around $20 \%$ for rental and subsidized housing. Agriculture and commercial properties make up the remaining $20 \%$ of the market.

Traditionally the Danish system has been dominated by fixed-rate mortgages, although adjustable-rate mortgages have become more popular in the last 15 years. Badarinza, Campbell, and Ramadorai (2015) report that the average share of adjustable-rate mortgages in Denmark was $45 \%$ in the period 2003-13, with a standard deviation of $13 \%$. At the beginning of our sample period in 2009, the adjustable-rate mortgage share was about $40 \%$.

\section{B. Refinancing}

Fixed-rate mortgage borrowers in Denmark have the right to prepay their mortgages without penalty. This is similar to the US system but differs from another leading fixedrate European mortgage system, the German system, where a fixed-rate mortgage can only be prepaid at a penalty that compensates the mortgage lender for any decline in interest rates since the mortgage was originated. However the prepayment system in Denmark also differs from the US system in several important respects.

The Danish mortgage system imposes minimal barriers to any refinancing that does not "cash out" (in a sense to be made more precise below). Danish borrowers can refinance their mortgages to reduce their interest rate and/or extend their loan maturity, without cashing out, even if their homes have declined in value so they have negative home equity. Related 
to this, refinancing without cashing out does not require a review of the borrower's credit quality. ${ }^{10}$ These features of the system imply that all mortgage borrowers can benefit from a decline in interest rates, even in a weak economy with declining house prices and consumer deleveraging.

The mechanics of refinancing in Denmark are as follows. The mortgage borrower must repurchase mortgage bonds corresponding to the mortgage debt, and deliver them to the mortgage lender. This repurchase can be done either at market value or at face value. The option to refinance at market value becomes relevant if interest rates rise; it prevents "lock-in" by allowing homeowners who move to buy out their old mortgages at a discounted market value rather than prepaying at face value as would be required in the US system. It also allows homeowners to take advantage of disruptions in the mortgage bond market by effectively buying back their own debt if a mortgage-bond fire sale occurs. In an environment of declining interest rates such as the one we study, the option to refinance at face value is relevant.

An important point is that mortgage bonds in Denmark are issued with discrete coupon rates, historically at integer levels such as $4 \%$ or $5 \%{ }^{11}$ This discreteness helps to ensure a liquid market for mortgage bonds. Market yields, of course, fluctuate continuously. Danish mortgage bonds can never be issued at a premium to face value, since this would allow instantaneous advantageous refinancing, and normally are issued at a discount; in other words, the market yield is somewhat above the discrete coupon at issue. This implies that to raise, say, DKK 1 million for a mortgage, bonds must be issued with a face value which is higher than DKK 1 million. Refinancing the mortgage requires buying the full face value of the bonds that were originally issued to finance it. Therefore the interest saving from refinancing in the Danish system is given by the spread between the coupon rate on the old

\footnotetext{
${ }^{10}$ Denmark does not have a system of continuous credit scores like the widely used FICO scores in the US. Instead, there is what amounts to a zero/one scoring system that can be used to label an individual as a delinquent borrower ("dårlig betaler") who has unpaid debt outstanding. A delinquent borrower would be unlikely to obtain a mortgage, but a borrower with an existing mortgage can refinance, without cashing out, even if he or she has been labeled as delinquent since the mortgage was taken out.

${ }^{11}$ More recently, bonds have been issued with non-integer coupons $(2.5 \%$ and $3.5 \%)$ in response to the current low-interest-rate environment.
} 
mortgage bond (not the yield on the mortgage when it was issued) and the yield on a new mortgage.

An example may make this easier to understand. Suppose that a household requires a loan of DKK 1 million (about $\$ 190,000$ or EUR 130,000) in order to purchase a house. Suppose that the market yield on a mortgage bond of the required term is $4.25 \%$, but the coupon rate on the bond is somewhat lower at $4 \%$. As a result of this difference between the coupon rate and the market yield, the DKK 1 million loan must be financed by issuing bonds in the market with a face value which is higher than DKK 1 million (say DKK 1.1 million). The principal balance of the mortgage is initially DKK 1.1 million.

Now consider what happens if market yields drop to $3.25 \%$. The borrower can refinance by purchasing the original mortgage bond at face value and delivering it to the mortgage bank. To fund the purchase, the borrower will issue new mortgage bonds carrying the current market yield of $3.25 \%$, and a lower discrete coupon (3\% in this example). The interest saving from refinancing is $4 \%-3.25 \%=0.75 \%$. This is the spread between the original coupon rate at issuance and the current market yield, rather than the spread between the old and new yields.

Since this transaction requires issuing a new mortgage bond with a market value of DKK 1.1 million and a face value above DKK 1.1 million, the principal balance of the mortgage increases as a result of the refinancing. ${ }^{12}$ However, it does not count as a cash-out refinancing provided that the market value of the newly issued mortgage bond is no greater than the face value of the old mortgage bond.

Cash-out refinancing does require sufficiently positive home equity and good credit status. For this reason, cash-out refinancing has been less common in Denmark in the period we examine since the onset of the housing downturn in the late $2000 \mathrm{~s}$. In our dataset $26 \%$ of refinancings are associated with an increase in mortgage principal of $10 \%$ or more, enough

\footnotetext{
${ }^{12}$ This may be regarded as the Danish equivalent of "points" in the US system, cash paid up front to lower the interest rate on a mortgage. The Danish system allows points to be borrowed, increasing the mortgage principal balance. We thank Susan Woodward for pointing out this analogy.
} 
to classify these as cash-out refinancings with a high degree of confidence. In the paper we present results that include these refinancings, but in the online appendix we report broadly similar results excluding them.

\subsection{Danish household data}

\section{A. Data sources}

Our dataset covers the universe of adult Danes in the period between 2008 and 2012, and contains demographic and economic information. We derive data from five different administrative registers made available through Statistics Denmark.

We obtain mortgage data from the Association of Danish Mortgage Banks (Realkreditrådet) and the Danish Mortgage Banks' Federation (Realkreditforeningen). The data cover the 5 largest mortgage banks with an aggregated market share of $94.2 \%$ of the market value of all mortgages in Denmark. The data contain the personal identification number of borrowers, as well as a mortgage id, and information on the terms of the mortgage (principal, outstanding principal, coupon, annual fees, maturity, loan-to-value, issue date, etc.) The mortgage data are available annually from 2009 to 2011.

We obtain demographic information from the official Danish Civil Registration System (CPR Registeret). These records include the individual's personal identification number (CPR), as well as their name; gender; date of birth; and the individual's marital history (number of marriages, divorces, and history of spousal bereavement). The administrative record also contains a unique household identification number, as well as CPR numbers of each individual's spouse and any children in the household. We use these data to obtain demographic information about the borrower. The sample contains the entire Danish population and provides a unique identifying number across individuals, households, and time.

We obtain income and wealth information from the official records at the Danish Tax Authority (SKAT). This dataset contains total and disaggregated income and wealth infor- 
mation by CPR numbers for the entire Danish population. SKAT receives this information directly from the relevant third-party sources, because employers supply statements of wages paid to their employees, and financial institutions supply information to SKAT on their customers' deposits, interest paid (or received), security investments, and dividends. Because taxation in Denmark mainly occurs at the source level, the income and wealth information are highly reliable.

Some components of wealth are not recorded by SKAT. The Danish Tax Authority does not have information about individuals' holdings of unbanked cash, the value of their cars, their private debt (i.e., debt to private individuals), pension savings, private businesses, or other informal wealth holdings. This leads some individuals to be recorded as having negative net financial wealth because we observe debts but not corresponding assets, for example in the case where a person has borrowed to finance a new car.

We obtain the level of education from the Danish Ministry of Education (Undervisningsministeriet). This register identifies the highest level of education and the resulting professional qualifications. On this basis we calculate the number of years of schooling.

Finally, we use data on medical treatments and hospitalizations from the Danish National Board of Health (Sundhedsstyelsen) to calculate the total number of days in hospital during the year. This dataset records medical treatments and discharges from hospitals.

\section{B. Sample selection}

Our sample selection entails linking individual mortgages to the household characteristics of borrowers. We define a household as one or two adults living at the same postal address. To be able to credibly track the ownership of each mortgage we additionally require that each household has an unchanging number of adult members over two subsequent years. This allows us to identify 2,727,782 households in 2011 (2,709,486 in 2010 and 2,691,140 in 2009). Of these 2,727,782 households, we are able to match $2,494,621$ households to a complete set of information from the different registers. The main missing information 
for the remaining households pertains to their educational qualifications, often missing on account of verification difficulties for immigrants.

To operationalize our analysis of refinancing, we begin by identifying households with a single fixed-rate mortgage. This is done in four steps. First we identify 953,099 households with a mortgage in 2009. Second, to simplify the analysis, we focus on households with a single mortgage throughout the sample period, leaving us with 702,834 households. Third, we focus on households with fixed-rate mortgages as these are the households who have financial incentives to refinance when interest rates decline. This leaves us with 281,698 households for the 2009 to 2010 refinancing decision, and 271,893 households for the 2010 to 2011 refinancing decision. Thus, in total we have 553,591 household observations across the two years. Finally, we expand the data to quarterly frequency using mortgage issue dates reported in the annual mortgage data, giving us a total of 2,146,395 quarterly refinancing decisions. $^{13}$

We observe a total of 84,111 refinancings across the two years: 61,133 in 2010 and 22,978 in 2011. Of these, 39,878 refinancings were from fixed-rate to adjustable-rate mortgages, and 44,233 from fixed-rate to fixed-rate mortgages (or in a minority of cases to capped adjustable-rate mortgages which have similar properties to true fixed-rate mortgages). We treat both types of refinancings in the same way and do not attempt to model the choice of an adjustable-rate versus a fixed-rate mortgage. ${ }^{14}$

Collectively, our selection criteria ensure that the refinancings we measure are undertaken for economic reasons. Refinancing in our sample occurs when a household changes from one fixed-rate mortgage to another mortgage (whether it is fixed- or adjustable-rate) on the

\footnotetext{
${ }^{13}$ This is less than the number of yearly observations times four $(2,214,364)$, because some households refinance from a fixed-rate mortgage to an adjustable-rate mortgage, and drop out of the sample in subsequent quarters. Our imputation of quarterly refinancings will be incorrect if a mortgage refinances twice in the same calendar year (since only the second refinancing will be recorded at the end of the year), but we believe this event to be exceedingly rare.

${ }^{14}$ The comparison of adjustable- and fixed-rate mortgages is complex and has been discussed by Dhillon, Shilling, and Sirmans (1987), Brueckner and Follain (1988), Campbell and Cocco (2003, 2015), Koijen, Van Hemert, and Van Niewerburgh (2009), Johnson and Li (2014), and Badarinza, Campbell, and Ramadorai (2015) among others.
} 
same property. Mortgage terminations that are driven by household-specific events, such as moves, death, or divorce, are treated separately by predicting the probability of mortgage termination, and using the fitted probability as an input into the Agarwal, Driscoll, and Laibson (2013) model of optimal refinancing. This approach differs from that of the US prepayment literature, which seeks to predict all mortgage terminations regardless of their cause.

\section{Descriptive statistics}

Table 1 summarizes the characteristics of Danish fixed-rate mortgages, and households' propensity to refinance them. These characteristics are broken out by the annual coupon rate on the underlying mortgage bonds. In addition to the annual coupon, borrowers pay an administration fee to the mortgage bank. This fee is roughly 70 basis points on average, and depends on the loan-to-value (LTV) ratio on the mortgage, but is independent of household characteristics.

The average fixed-rate mortgage has an outstanding principal of DKK 905,000 (about $\$ 173,000$ or EUR 118,000) and 23.3 years to maturity by the end of 2009. The outstanding principal corresponds to a loan-to-value ratio of $56.3 \%$ on average. From 2009 to 2010, 21.7\% of all fixed-rate mortgages in our sample were refinanced, $10.0 \%$ to adjustable-rate and $11.7 \%$ to fixed-rate mortgages. As expected, the refinancing probability depends on the coupon rate of the mortgage bond underlying the old mortgage. For mortgages with a coupon of $3 \%$ and $4 \%$ the propensities to refinance are $3.9 \%$ and $5 \%$, respectively. ${ }^{15}$ For mortgages with a $5 \%$ coupon, which in 2009 accounted for roughly half of all fixed-rate mortgages, the propensity to refinance is $20.3 \%$. The propensities to refinance are $55.6 \%$ and $43.7 \%$ for mortgages with coupon rates of $6 \%$ and $7 \%$ or more, respectively.

In 2011 the propensity to refinance was lower than in 2010 . In total, only $8.5 \%$ of all fixedrate mortgages were refinanced, $3.7 \%$ to adjustable-rate and $4.8 \%$ to fixed-rate mortgages.

\footnotetext{
${ }^{15}$ Mortgage bonds with a $3 \%$ coupon were issued in 2005 during a previous period of relatively low mortgage rates. Most of the underlying mortgages for these bonds have a relatively low maturity of 10 years, or in some cases 20 years. These mortgages account for only a very small fraction of our dataset.
} 
Still, we again see an increasing propensity to refinance as the coupon rate increases. For $3 \%$ coupon mortgages the propensity to refinance was a modest $3.1 \%$, while the refinancing propensity for mortgages with a $6 \%$ coupon or higher lies between $11.7 \%$ and $15.9 \%$.

Table 2 provides a comprehensive set of descriptive statistics for all households with a fixed-rate mortgage, as well as a comparison of household characteristics between refinancing and non-refinancing households, measured in January of each year. Around $25 \%$ of all households consist of a single member, and $64 \%$ are married couples. The remainder are cohabiting couples. Around $41 \%$ of households have children living in the household. Table 2 also reports that $1.0 \%$ of households got married, $4.2 \%$ experienced the birth of a child, and $3.6 \%$ experienced a negative health shock during the last year. We define a negative health shock as occurring whenever a member of a household receives medical treatment at a hospital (on an inpatient or outpatient basis) on 5 days or more during the last year, and received such treatment on fewer than 5 days in the year before.

We also have direct measures of financial literacy, defined as a degree in finance or economics, or professional training in finance, for at least one member of the household. $4.6 \%$ of households are financially literate in this strong sense. A larger fraction of households, $12.9 \%$, have members of their extended family (including non-resident parents, siblings, inlaws, or children) who are financially literate.

In our empirical analysis we use demeaned ranks of age, education, income, financial wealth, and housing wealth rather than the actual values of these variables. A table in the appendix reports selected percentiles of the underlying distribution for all households, and separately for refinancing and non-refinancing households.

Columns 2 to 7 of Table 2 report differences in household characteristics between refinancing and non-refinancing households in the full sample (column 2), the years 2010 and 2011 (columns 3 and 4), and subsamples of more highly educated (top quartile), married, and wealthier (top quartile) households (columns 5 to 7 ). A positive number means that the average characteristic is larger for refinancing households than for non-refinancing house- 
holds. The differences between refinancers and non-refinancers are generally robust across subsamples. For example, refinancing households are more likely to be married and less likely to be single, more likely to have children, to get married, and to experience the birth of a child, and less likely to have a negative health shock. Our measures of financial literacy are also higher for refinancing households.

Some important patterns emerge in the comparison of ranked variables across refinancers and non-refinancers. Refinancers are younger and better educated, and have higher income and housing wealth but lower financial wealth. The appendix shows that the same patterns appear when we estimate logit refinancing models that include all demographic variables simultaneously with refinancing incentives. We now develop a mixture model that can be used to explore such effects in greater detail.

\section{$3 \quad$ A Model of Refinancing Types}

\subsection{A mixture model of refinancing}

\section{A. Refinancing conditional on household type}

Consider a model of mortgage choice in which the likelihood of observing a household $i$ refinancing its fixed-rate mortgage at time $t$ (the event $y_{i, t}=1$ ) is determined by the type of the household $h$ (a main target of our modelling efforts), which affects households' perceived financial incentives to refinance $I_{h}\left(z_{i, t}\right)$, and a standard logistic distributed stochastic choice error $\epsilon_{i, t}$ following Luce (1959).

In the model, households of type $h$ have a probability of refinancing given by:

$$
p_{i, t}^{h}\left(y_{i, t}=1 \mid \nu_{h}, \beta_{h}\right)=p_{i, t}^{h}\left(\nu_{h}+e^{\beta_{h}} I_{h}\left(z_{i, t}\right)+\epsilon_{i, t}>0\right) .
$$

In the above equation, $z_{i, t}$ contains both mortgage characteristics as well as household char- 
acteristics $s_{i, t}$, which together determine the household's perceived financial incentives to refinance. $\nu_{h}$ is the baseline probability of refinancing for households of type $h . \beta_{h}$ captures the reaction to incentives, modelled as an exponent to ensure that households react nonperversely to incentives, as higher incentives always lead to an increase in the probability of refinancing for any value of $\beta_{h}$.

This specification implies that the likelihood contribution of each choice of household type $h$ is:

$$
\mathcal{L}_{i, t}^{h}\left(\beta_{h}, \nu_{h}\right)=\Lambda\left(\left[2 y_{i, t}-1\right]\left[\nu_{h}+e^{\beta_{h}} I_{h}\left(z_{i, t}\right)\right]\right)
$$

where $\Lambda($.$) is the inverse logistic function, \Lambda(x)=e^{x} /\left(1+e^{x}\right)$. For a single type, this model of household choice underlies the commonly used logit regression.

\section{B. Household characteristics and mixing proportions}

Our model considers households $i$ as a mixture of proportions of these different types, each with a mixing weight $0<\delta_{i}^{h}<1$, constructed such that total weights for each household sum to one, i.e., $\sum_{h} \delta_{i}^{h}=1$.

We can now specify the likelihood contribution for household $i$ as a finite mixture of proportions. This can also be interpreted as each household having a probability $\delta_{i}^{h}$ of being type $h$ :

$$
\mathcal{L}_{i, t}\left(\delta_{i}^{h}, \nu_{h}, \beta_{h}\right)=\sum_{h} \delta_{i}^{h} \mathcal{L}_{i, t}^{h}
$$

To ensure $\sum_{h} \delta_{i}^{h}=1$ we construct the mixing proportions as

$$
\delta_{i}^{h}=e^{\xi_{i}^{h}} / \sum e^{\xi_{i}^{h}}
$$

We allow for observable household characteristics to influence the relative weights on the different types, specifying $\xi_{i}^{h}=\chi_{h}^{\prime} s_{i t}$, where as before, $s_{i t}$ captures household demographic characteristics. 
This leads to the household $i \log$ likelihood function over our sample specified as:

$$
\ln \mathcal{L}\left(\chi_{h}, \nu_{h}, \beta_{h}\right)=\sum_{t} \sum_{i} \ln \left(\sum_{h} \delta_{i}^{h} \mathcal{L}_{i, t}^{h}\right)
$$

\subsection{Household types}

\section{A. Levelheads and woodheads}

We define two different types of households, levelheads (type $h=L$ ) and woodheads (type $h=W$ ), who differ in their values of $\nu_{h}$ and $\beta_{h}$, as well as in the incentives $I_{h}\left(z_{i, t}\right)$ that they perceive. Levelheads are approximately rational, while woodheads are inattentive to refinancing incentives (we borrow their name from Deng and Quigley 2012, and from mortgage industry slang).

Woodheads ignore incentives and refinance at a constant rate $\nu_{W}$. To represent this behavior we set $I_{W}\left(z_{i, t}\right)$ and $\beta_{W}$ to zero. We allow $\nu_{W}$ to vary with household demographic characteristics $s_{i, t}$.

Levelheads respond solely to the incentives that they perceive, and have no base rate of refinancing that is not contingent on incentives. To represent this behavior we set $\nu_{L}$ to zero. We estimate a levelhead sensitivity to incentives $\beta_{L}$, a fixed number that does not vary with demographic characteristics.

To illustrate the implications of this model, Figure 1 plots refinancing probabilities against incentives estimated in our Danish data set, using the simplest possible mixture model in which demographic characteristics play no role. A zero incentive is defined as the interest saving at which a levelhead household has a $50 \%$ probability of refinancing. The levelhead refinancing probability, shown as a dot-long dashed line, is symmetric around the zero incentive, increasing rapidly from near zero at a negative incentive of about $-1 \%$ to almost one at a positive incentive of about $1 \%$. The woodhead refinancing probability, shown as 
a dot-short dashed line, is constant at slightly less than $1 \%$ regardless of the level of the incentive. The estimated fraction of levelheads is $12 \%$, so the overall estimated refinancing probability is the dashed line which is slightly less than $13 \%$ even at very high incentive levels. The empirically observed refinancing probability in our dataset is shown as the solid line.

\section{B. Levelhead refinancing incentives}

To measure the incentives to which levelheads respond, we follow ADL (2013). The incentive is the difference between the coupon rate on the mortgage bond corresponding to the current mortgage $C_{i t}^{\text {old }}$, less the interest rate on a new mortgage $Y_{i t}^{\text {new }}$, less a threshold level $O_{h}\left(z_{i t}\right)$ :

$$
I_{h}\left(z_{i, t}\right)=C_{i, t}^{\text {old }}-Y_{i, t}^{\text {new }}-O_{h}\left(z_{i, t}\right) .
$$

The function $O_{h}\left(z_{i t}\right)$ captures a variety of costs associated with refinancing. For levelheads, this function takes the fixed costs of refinancing into account, but in addition, it captures the option value of waiting for further interest-rate declines. We measure this option value in our empirical analysis using the closed-form optimal refinancing solution of ADL:

$$
\begin{aligned}
O_{L}\left(z_{i, t}\right) & =\frac{1}{\psi}[\phi+W(1-\exp (-\phi))], \\
\psi & =\sqrt{\frac{2\left(\rho+\lambda_{i, t}\right)}{\sigma}}, \\
\phi & =1+\psi\left(\rho+\lambda_{i, t}\right) \frac{\kappa_{i, t}}{m_{i, t}(1-\tau)} .
\end{aligned}
$$

Here $W($.$) is the Lambert W$-function, $m_{i, t}$ is the size of the mortgage for household $i$ at time $t, \lambda_{i, t}$ is the expected exogenous rate of decline in the real value of the mortgage, and $\kappa_{i, t}$ is the fixed cost of refinancing. All of these parameters can in principle vary across households. Marketwide parameters include the volatility of the interest rate $\sigma$, the marginal tax rate $\tau$ 
that determines the tax benefit of mortgage interest deductions, and the discount rate $\rho .{ }^{16}$

Following ADL we define $\lambda_{i, t}$ and $\kappa_{i, t}$ as

$$
\begin{aligned}
& \lambda_{i, t}=\mu_{i, t}+\frac{Y_{i, t}^{\text {old }}}{\exp \left(Y_{i, t}^{\text {old }} T_{i, t}\right)-1}+\pi_{t}, \\
& \kappa_{i t}=f .
\end{aligned}
$$

Here $\mu_{i, t}$ can be interpreted as the probability of exogenous mortgage termination, $Y_{i t}^{\text {old }}$ is the yield on the household's pre-existing ("old") mortgage, $T_{i, t}$ is the number of years remaining on the mortgage, $\pi_{t}$ is the inflation rate, and $f$ is the fixed cost of refinancing. Our initial model uses a mixture of the recommended parameters in ADL and sensible values given the Danish context, i.e., $\sigma=0.0074, \tau=0.33, \rho=0.05$, and $f=\operatorname{DKK} 10,000$ (about $\$ 1,900$ or EUR 1,300). $\pi_{t}$ is set equal to realized consumer price inflation over the past year, a standard proxy for expected inflation that varies between $2.0 \%$ and $3.0 \%$ during our sample period.

To allow for a more realistic measurement of $\lambda_{i, t}$, we estimate $\mu_{i, t}$ at the household level using additional data. Mortgage termination can occur for many reasons, including the household relocating, experiencing a windfall and paying down the principal amount, selling the property, or simply because the household ceases to exist because of death or divorce. (We exclude refinancing from the definition of mortgage termination.) Without seeking to differentiate these causes, to estimate $\mu_{i, t}$ we use all households with a single fixed-rate mortgage, and estimate, for each year in the sample:

$$
\mu_{i, t}=\operatorname{Pr}(\text { Termination })=p\left(\mu^{\prime} s_{i, t}+\epsilon_{i, t}>0\right), \epsilon_{i, t} \sim N(0, \sigma),
$$

using the same vector $s_{i, t}$ of household characteristics. We use the predicted termination

\footnotetext{
${ }^{16}$ Although the Danish tax system is progressive, the tax benefit of mortgage interest deductions is calculated at a fixed tax rate. ADL also present an approximation to the solution (7) that does not require the use of the Lambert $W$-function. We used the approximation in the first draft of this paper, but found that its accuracy deteriorates unacceptably for mortgages with higher ADL thresholds.
} 
probabilities from this model for each household $i$ at time $t$ to construct $\lambda_{i, t}$.

Figure 2 shows a histogram of the estimated mortgage termination probabilities, with a red line showing the position of the ADL suggested "hardwired" level of $10 \%$ per annum. The mean of our estimated termination probabilities is $10.6 \%$, larger than the median of $7.5 \%$ because the distribution of termination probabilities is right-skewed. The standard deviation of this distribution is $9.2 \%$.

Finally, we note two minor limitations of the ADL formula in our context. First, it gives us the incentive for a household to refinance from a fixed-rate mortgage to another fixedrate mortgage. Some households in our sample refinance from fixed-rate to adjustable-rate mortgages, implying that they perceive a new ARM as even more attractive than a new FRM. We do not attempt to model this decision here but simply use the ADL formula for all initially fixed-rate mortgages and refinancings, whether or not the new mortgage carries a fixed rate.

Second, the ADL formula ignores the fact, unique to the Danish system, that refinancing may increase the mortgage principal balance because the coupon on the new mortgage bond is lower than the market yield. This increase in the mortgage principal has no economic effect except in the event that interest rates decline further in the future, leading the household to consider refinancing the new mortgage. ${ }^{17}$ The value of the refinancing option attached to the new mortgage is determined by the new mortgage bond coupon, and is lower than that assumed by the ADL formula whenever that coupon is lower than the current market yield, in other words whenever the mortgage principal increases. Fortunately this effect is extremely small, as shown by ADL in a comparison of their formula with an earlier analysis by Chen and Ling (1989). The chief difference between the two papers is that Chen and Ling's baseline calculations exclude the possibility of subsequent refinancings. The difference between the ADL and Chen-Ling thresholds is therefore an upper bound on the effect of principal balance

\footnotetext{
${ }^{17}$ Importantly, the principal balance does not play any special role in the event of mortgage default. Even in delinquency, the household has the option to pay the market value or the face value of the mortgage bond, whichever is lower. Note also that delinquency is rare in Denmark, affecting only about $0.5 \%$ of the households in our sample.
} 
increase in the Danish system. Equating their parameters to Chen and Ling's values, ADL find that the threshold difference is only 10 basis points (on a base of 218 basis points) when the refinancing cost is 2 points. This difference is small enough that it would make no meaningful difference to any of our empirical findings. ${ }^{18}$

\section{Dynamic effects}

There are several reasons why the weights on different household types may depend on the date at which a household's mortgage was issued and the date at which the refinancing decision is observed. There may be pure time effects of the current date, for example if the population of mortgage borrowers becomes more aware of rational prepayment policy over time. There may be pure mortgage age effects if households avoid refinancing mortgages in the first few quarters after issue, or if they become less attentive to mortgages that have been outstanding for many years. The literature on prepayment modeling for US households, where demographic characteristics are not observed, pays particular attention to such mortgage age effects (see for example Kang and Zenios 1992, Stanton 1995, or Hall 2000).

There may also be effects resulting from changes over time in the type composition of a particular cohort of mortgages. To understand this, consider two alternative extreme views about type assignment in our model. One extreme view is that each household draws a new type assignment each period, from a fixed distribution determined by its demographic characteristics. Given these characteristics, the probability of being a woodhead does not depend on the past behavior of the household; even if a household has failed to refinance for many periods, this does not make it any more likely to be a woodhead this period. According to this view, woodhead and levelhead behavior are temporary states, akin to being asleep or awake, rather than persistent conditions.

\footnotetext{
${ }^{18}$ Chen and Ling's parameter values are close enough to those in our paper for this comparison to be relevant. Their value of $\kappa /(1-\tau)$ is 2 , while ours is 1.5 , implying that our thresholds are slightly smaller than theirs. Their calibrated annual interest rate volatility is 0.012 , whereas ours is 0.0074 , but this difference has an ambiguous effect on the value of future refinancing options, because lower interest rate volatility lowers the refinancing threshold but also lowers the probability that any fixed threshold will be hit in the future. We thank Susan Woodward for highlighting this issue.
} 
The opposite extreme view is that woodhead and levelhead behavior are permanent characteristics of individual households. If this is the case, then past behavior - and past incentives which drive levelhead behavior - should alter the conditional probability that a household is one or the other type. Specifically, during periods of positive refinancing incentives driven by declining interest rates, levelheads should refinance more rapidly than woodheads. With permanent type assignments, the remaining population of outstanding mortgages will have a higher fraction of woodheads in the future. Conversely, the fraction of woodheads declines during periods of negative refinancing incentives when only woodheads refinance.

Our ability to identify such dynamic effects is limited in several respects. There is the general problem that age, time, and cohort effects can never be identified in a panel without the application of some theoretical restrictions. And there is the more specific problem that we observe only two years of refinancing decisions. Given these limitations, we proceed informally by including in our vector of household characteristics a set of dummies for the quarter of mortgage issuance and the current quarter. (Dummies for the interaction of issuing quarter and current quarter add many coefficients but almost no explanatory power, so we exclude them.) We then interpret the patterns of coefficients on these dummies in the light of these theories of mortgage refinancing behavior.

\section{Empirical Results}

\subsection{Refinancing incentives}

During our sample period Danish mortgage rates declined from the levels that had prevailed in the late 2000s, back to levels last seen in 2005. This pattern is illustrated by Figure 3, which plots the history of 30-year Danish mortgage rates from 2003 . In the middle of 2010 the mortgage rate bottomed out just above 4\%, before rising back above $5 \%$ in early 
2011, and then declining again to below $4 \%$ later in the year, and even further through 2012. Throughout our data analysis, we treat each quarter as a single observation, and use the minimum weekly average mortgage rate during the quarter to calculate refinancing incentives.

Table 3 summarizes the cross-sectional distribution of refinancing incentives. The top panel of the table shows the interest rate spread between the coupon rate on the mortgage bond corresponding to the old mortgage, less the currently available mortgage rate. To ensure that we match old to new mortgages appropriately, we match using the remaining tenure on the old mortgage, within 10-year bands. That is, in each quarter, for mortgages with 10 or fewer years to maturity, we use the average 10 year mortgage bond yield to compute incentives, and for remaining tenures between 10-20 years (>20 years) we use the average 20 year (30 year) bond yield. These 10, 20, and 30 year yields are calculated as value-weighted averages of yields on all newly issued mortgage bonds with maturities of 10 , 20 , and 30 years, respectively.

The median interest spread computed in this fashion was 19 basis points in 2010 and 45 basis points in 2011, with wide cross-sectional variation. In 2010, for example, the 5th percentile of the interest rate spread was roughly -100 basis points, while the 95 th percentile was 182 basis points.

The second panel of the table reports the ADL (2013) threshold that justifies refinancing. The median threshold is 106 basis points in 2010 and 110 basis points in 2011, but once again there is wide cross-sectional variation, from 60 basis points at the 5 th percentile to 283 basis points at the 95 th percentile in 2010 . The cross-sectional distribution of thresholds is rightskewed because, in the presence of fixed refinancing costs, a very high interest saving is needed to justify refinancing a small mortgage or a mortgage with only a few years left to maturity.

The third panel subtracts the ADL threshold from the interest rate spread for each mortgage to calculate the overall refinancing incentive perceived by rational (levelhead) mortgage 
borrowers. The median incentive was negative at -85 basis points in 2010 and -93 basis points in 2011, indicating that most mortgage borrowers should not have refinanced in these years. However, just over $21 \%$ of mortgage-quarters in our sample have positive refinancing incentives. The 95 th percentile incentive was 53 basis points in 2010 and 44 basis points in 2011 .

\subsection{Errors of commission and errors of omission}

A simple way to use these estimates is to calculate the incidence of refinancing mistakes. These fall into two main categories. Borrowing the terminology of Agarwal, Rosen, and Yao (2012), "errors of commission" are refinancings that occur at an interest-rate saving below the ADL threshold, while "errors of omission" are failures to refinance that occur above the ADL threshold.

Table 4 reports the frequency of these two types of error. We define an error of commission as a refinancing with an interest rate saving below the ADL threshold less $k \%$, and an error of omission as a household-quarter where a refinancing does not occur even though the interest saving is above the ADL threshold plus $k \%$. The additional error cutoff level of $k$ percentage points is introduced to take account of uncertainty in the ADL threshold. For a given $k$, households are classified as making errors of omission if they fail to refinance when incentives are greater than $k$, and errors of commission if they refinance with incentives less than $-k$, while incentives between $-k$ and $k$ cannot generate either kind of error. In addition, we classify a refinancing as an error of commission only if the refinancing does not involve cash-out or maturity extension, since these alterations in mortgage terms could be sufficiently advantageous to justify refinancing even at a modest interest saving below the ADL threshold.

Table 4 shows that in our sample period, far more household-quarters have negative refinancing incentives $(1,688,215$ household-quarters in the case of $k=0)$ than have positive refinancing incentives $(458,180$ in the case of $k=0)$. However, within the large first group 
errors of commission are relatively rare, occurring slightly more than $1 \%$ of the time for error thresholds $k=0$ or $k=0.25$. Within the small second group errors of omission are extremely common, occurring almost $90 \%$ of the time for $k=0$ and $87 \%$ of the time for $k=0.25$.

While these numbers reflect a count of household-quarters rather than households, so that refinancing delays of a few quarters generate several errors of omission, the high incidence of errors of omission is nonetheless striking. It is consistent with the fact that we observe some large positive refinancing incentives in our dataset, which we could not do unless there had been errors of omission before the start of our sample period. To illustrate this point, Figure 4 plots the history of refinancing activity in relation to the currently available mortgage rate, dividing households by the coupon rate on their old mortgage bond. The figure illustrates the prevalence of errors of omission, as we can see a small fraction of households even in late 2011 still refinancing out of $7 \%$ mortgages despite the sharp dips in interest rates in 2010 and the overall low levels of interest rates. However, movements in interest rates do stimulate refinancing activity as we see from the refinancing spikes in the early part of 2010 . These results support the focus of the literature on errors of omission, but also motivate the more careful econometric analysis of the determinants of refinancing that we undertake in the next section, distinguishing inattention and inertia using our mixture model.

Table 5 relates errors of commission and errors of omission to demographic characteristics of households. The left hand panel of the table has an error cutoff of $k=0$, while the right hand panel sets $k=0.25$. In each column of the table, we report the mean difference for each of the demographic characteristics listed in the rows, between refinancing and nonrefinancing households. Positive (negative) numbers under columns marked "Increases in Errors of Commission" signify demographic characteristics which are associated with shifts of household-quarters into (out of) such errors, and similarly positive (negative) numbers under columns marked "Reductions in Errors of Commission" signify demographic characteristics which are associated with shifts of household-quarters out of (into) such errors. 
Almost all the household characteristics shown in Table 5 shift the refinancing probability in the same direction regardless of the incentive. Therefore characteristics such as marriage and education that reduce the incidence of errors of omission also increase the incidence of errors of commission. This suggests that household characteristics have an important effect on the baseline probability of refinancing, as well as the attention to incentives, a result that we indeed find when we estimate our more structural mixing model of refinancing behavior.

In Table 6, we attempt to quantify the costs of errors of omission in a simple fashion. A full analysis would require simulating interest rates, using either the interest rate process assumed by ADL or an empirical model of Danish interest dynamics. One would then track mortgages along simulated interest paths, calculating the mortgage interest and refinancing costs along each path for each possible refinancing threshold, and finally average across paths to measure the ex ante cost of a suboptimal refinancing policy. However, such an analysis would take us far afield from our empirical orientation in this paper.

Accordingly, we undertake a much simpler empirical exercise to calculate the realized excess interest paid on mortgages above the ADL threshold, net of refinancing costs. For each mortgage with an interest saving above the ADL threshold in each quarter, we calculate the difference between the interest paid on that mortgage, and the interest it would pay if it refinanced and rolled the fixed refinancing cost into the principal. We then divide by mortgage principal on these mortgages (in the top panel) or by total principal of all outstanding mortgages (in the bottom panel) and present averages for 2010, 2011, and the two years together.

Table 6 shows that along the realized path for Danish interest rates, errors of omission cost the households making them almost $1.5 \%$ on average in our sample period, if we assume a zero tolerance threshold $k$. As we increase $k$, we identify more serious errors and the costs rise, to $1.9 \%$ with $k=0.25,2.1 \%$ with $k=0.5$, and $4.0 \%$ with an extreme $k=2$. Relative to the entire Danish mortgage market, these costs are 36 basis points with a zero $k, 26$ basis points with $k=0.25,21$ basis points with $k=0.5$, and only 2 basis points if we 
go to the extreme $k=2$. The decline in estimated costs relative to the entire market, as we increase $k$, is due to the fact that more extreme errors are less common, so while they have serious consequences for a few borrowers they are not as consequential in the Danish mortgage system as a whole.

While these numbers admittedly come from simple calculations conditional on a single path for interest rates, they suggest that errors of omission can have substantial costs. This finding is consistent with evidence reported in Miles (2004), Campbell (2006), Agarwal, Rosen, and Yao (2012), and Keys, Pope, and Pope (2014).

\subsection{Mixture models}

\section{A. Model comparisons}

The first column of Table 7 estimates a baseline mixture model with a constant refinancing probability for woodheads and a constant proportion of levelheads (and therefore of woodheads) in the population. A low proportion of levelheads indicates that the population is relatively inattentive to incentives, and a low refinancing probability for woodheads indicates a high level of inertia, controlling for the level of attention.

The estimated model, illustrated earlier in Figure 1, implies that woodheads refinance each quarter with probability $0.9 \%$, and $85 \%$ of the population are woodheads. The remaining $15 \%$ are levelheads, who refinance with probability $10 \%$ when the incentive is $-0.88 \%$ (that is, when the raw interest spread is $0.88 \%$ lower than the ADL threshold), $25 \%$ when the incentive is $-0.43 \%, 50 \%$ when the incentive is zero, $75 \%$ when the incentive is $0.43 \%$, and $90 \%$ when the incentive is $0.88 \%$. This model has a pseudo- $R^{2}$ statistic of $9.7 \%$.

The next two columns of Table 7 allow demographic characteristics, as well as issuingquarter, current-quarter, and mortgage issuer dummies, to shift first the woodhead refinancing probability only and then the proportion of levelheads only. 
Agarwal, Driscoll, Gabaix, and Laibson (2009) report that age has a nonlinear effect on many financial decisions, with financial sophistication increasing among younger people as they gain experience, and decreasing among older people perhaps because of cognitive decline. Education, income, and financial and housing wealth may also have different effects among less educated and poorer people than among better educated and richer people. We therefore want to allow for nonlinear effects of the ranked variables on refinancing probabilities. The appendix shows that results are quite similar whether we do this using a piecewise linear function with a kink at the median (achieved by adding the absolute value of the demeaned rank to the regression), or using a quadratic function (by adding twice the squared demeaned rank, a normalization that allows direct comparison of the coefficients in the two specifications). Accordingly we proceed with the quadratic specification and report these results in Table 7.

We see very similar patterns of demographic effects on both the woodhead refinancing probability and the proportion of levelheads. Demographic characteristics that change the baseline refinancing probability of woodheads almost always change the fraction of levelheads in the demographic group in the same direction. Only a few effects, notably the nonlinear effect of housing wealth, seem to be meaningfully different across these two models.

The final two columns of Table 7 report a single model in which we allow household characteristics and mortgage dummies to influence both the woodhead refinancing probability and the proportion of levelheads simultaneously. This is the main model we use to interpret refinancing behavior among Danish households, and we now examine its properties in detail.

To illustrate the fit of this model, in Figure 5 we show the sample distribution of incentives, together with the observed sample refinancing probability at each incentive level. As previously discussed, most incentives are negative but the refinancing probability increases strongly around the zero level, peaking at an incentive slightly above $1 \%$. Very few observations have positive incentives greater than this, so the observed sample refinancing probability at high incentive levels is based on limited data and is correspondingly noisy. 
In Figure 6 we show the observed refinancing probability together with the model's predicted refinancing probability and the estimated fraction of levelheads in the mortgage pools with each incentive level. The model captures the runup in refinancing probability well until an incentive of about $0.8 \%$. Above this level it continues to track the spikes and dips in refinancing probability, but does not capture their magnitudes. The fraction of levelheads in the population is estimated to be largest among mortgages with incentives between $-1 \%$ and $2 \%$ (the great bulk of the distribution illustrated in Figure 5), and lower in the extreme right tail of the incentive distribution.

\section{B. Demographic effects}

The demographic effects we estimate in our mixture model are broadly consistent with those discussed earlier using simpler statistics. To show more clearly the effects of the ranked variables - age, education, income, financial wealth, and housing wealth - we present two figures that show the marginal estimated effect of the variable on the probability that a household is a levelhead (Figure 7) and on the woodhead refinancing probability (Figure 8). ${ }^{19}$

Figure 7 shows that age has a negative effect on the levelhead probability among younger households. Controlling for other demographic characteristics, the youngest households are almost $4 \%$ more likely to be levelheads than middle-aged or older households. ${ }^{20}$ Education has a modest positive effect on the levelhead probability.

Income has a hump-shaped effect on the levelhead probability, peaking at about the 70th percentile of income; financial wealth has a negative effect, particularly among poorer

\footnotetext{
${ }^{19}$ Figures in the appendix illustrate the total effects of each variable (that is, the average estimated levelhead probability and estimated woodhead refinancing probability for households in each percentile of the distribution, taking account of the changes in all other demographic characteristics that are associated with the change in the ranked variable of interest).

${ }^{20}$ The appendix shows that the age effect is somewhat weaker if we estimate a model with an ADL incentive calculated from a fixed moving probability, as in ADL, rather than a household-specific moving probability. The reason is that young households are more likely to move, so their ADL thresholds are higher; neglecting this effect makes young households appear more likely to be woodheads. The appendix also shows that the age effect is somewhat weaker if we exclude cash-outs and maturity extensions, because younger households are more likely to undertake these sorts of refinancing.
} 
households; and housing wealth has a positive effect among households with higher-valued homes. These patterns are consistent with a tradeoff between increased sophistication among households with higher income and wealth, and reduced significance of mortgage costs among households with high income and financial wealth relative to housing wealth.

Figure 8 shows that the woodhead refinancing probability declines with age among younger households, is relatively little affected by education, income or housing wealth, and declines strongly with financial wealth. A comparison of Figures 7 and 8, and the numbers reported in Table 7, highlight that many of the estimated demographic effects shift the baseline refinancing probability and the proportion of levelheads in the same direction. The correlation between these variables is 0.62 in the full dataset, but we can reject the hypothesis that this correlation is perfect.

In summary, Danish household refinancing behavior cannot be described by a simple model in which only attention to incentives varies across households. As attention diminishes (captured here by a lower levelhead probability), households converge to a baseline refinancing probability that also depends on demographics, and which tends to be lower in demographic groups that pay less attention to incentives. In other words, inattention and inertia are positively correlated in the cross section.

However, the correlation of these household attributes is not perfect. Some demographic effects operate differently on inattention and inertia: for example, single males pay greater attention to incentives but also have greater residual inertia, while negative health shocks increase inertia without reducing attention. Income and education increase attention among lower-income and less educated households, but have only very weak effects on inertia. Because of such divergent demographic effects, we can reject a model that imposes proportionality between inattention and inertia, despite the positive cross-sectional correlation between these variables. 


\section{Issuing-quarter and current-quarter effects}

Figures 9 and 10 plot the estimated coefficients on issuing-quarter dummies, for the woodhead refinancing probability and the probability that a household is a levelhead, respectively. The woodhead refinancing probability in Figure 9 rises for about three years and then remains fairly flat on average, although with substantial fluctuations around that average. This shape is broadly consistent with the PSA model established by the Public Securities Association as a benchmark description of US prepayment behavior, in which prepayments increase linearly during the first 31 months of mortgage life and remain flat thereafter (Veronesi 2010, p. 296 and Figure 8.5). ${ }^{21}$

The levelhead probability in Figure 10 is generally declining with the age of the mortgage, but it rises substantially for mortgages issued between mid-2004 and mid-2006. These mortgages have experienced relatively few periods of positive refinancing incentives during their lifetime, as illustrated by the dashed line in Figure 10. This pattern suggests that mortgage borrowers may have persistent type assignments, not perfectly captured by the demographic variables in the model, and that levelhead borrowers have disproportionately exited mortgage cohorts with positive past refinancing incentives.

An alternative way to evaluate this possibility is to look at the coefficients on currentquarter dummies. There are only eight quarters in our sample, so we do not undertake a formal structural analysis using our whole panel. Instead we undertake a simple analysis of the way in which the levelhead probabilities implied by the current-quarter dummies move in relation to refinancing rates.

For this purpose, consider a homogeneous continuum of households for which the fraction of levelheads is $\delta_{t}$ at the beginning of time $t$. Write the refinancing probability at time $t$ as $r_{L t}$ for levelheads and $r_{W}$ for woodheads. After refinancing at time $t$, the pool of mortgages is smaller. For each unit mass at the beginning of time $t$, the mass is now

\footnotetext{
${ }^{21}$ Note however that PSA and other US prepayment models apply to all prepayments, not just the refinancings we study in this paper.
} 
$\left(1-r_{L t}\right) \delta_{t}+\left(1-r_{W}\right)\left(1-\delta_{t}\right)$. The levelhead fraction at the end of the period is therefore

$$
\delta_{t}^{*}=\frac{\left(1-r_{L t}\right) \delta_{t}}{\left(1-r_{L t}\right) \delta_{t}+\left(1-r_{W}\right)\left(1-\delta_{t}\right)}=f\left(\delta_{t}, r_{L t}, r_{W}\right)
$$

Now suppose that at the end of the period (after refinancing but before the beginning of the next period), a fraction $\gamma$ of all households retain their type while a fraction $(1-\gamma)$ have their types reassigned randomly. Conditional on type reassignment, the probability that a household is a levelhead is $\bar{\delta}$. Then the new mixing weight on levelheads, at the start of time $t+1$, is

$$
\delta_{t+1}=\gamma \delta_{t}^{*}+(1-\gamma) \bar{\delta}=\gamma f\left(\delta_{t}, r_{L t}, r_{W}\right)+(1-\gamma) \bar{\delta}
$$

The coefficient $\gamma$ captures the persistence of type assignments. When $\gamma=0$, type assignments are purely temporary and the incentive history has no effect on the levelhead fraction which is always $\bar{\delta}$ in every period. When $\gamma=1$, individual households have permanent type assignments and the levelhead fraction changes only with selection of levelheads or woodheads out of the mortgage pool in response to incentives. Intermediate values of $\gamma$ imply that mortgage refinancing incentives affect the levelhead fraction temporarily, but not permanently.

Given a set of levelhead probabilities $\delta_{t}$ and type-specific refinancing probabilities estimated from our model, we can construct $\delta_{t}^{*}$ from equation (13) and then estimate equation (14) by ordinary least squares regression, either imposing that $\bar{\delta}$ is the eight-quarter sample mean of $\delta_{t}$ or estimating it from a free regression intercept. We use three alternative sets of $\delta_{t}$ and refinancing probabilities, based on the simple model of the first column of Table 7 that includes no demographics; the full model in the right two columns of Table 7, evaluated at the sample mean for all demographic variables; and the full model where we take the cross-sectional mean of the levelhead probability and refinancing probabilities. With two treatments of the intercept, these three cases give us six regressions. In all cases we estimate $\gamma$ between 0.6 and 0.7 , and $\bar{\delta}$ between 0.1 and 0.15 . The appendix provides further details 
of this exercise.

Putting the issuing-quarter and current-quarter results together, there is suggestive evidence of persistence in type assignments that creates "burn-out": a tendency for a group of households to become less responsive to positive refinancing incentives over time, as the more responsive members of the group are selected out. However, the limited time dimension of our panel dataset prevents us from pursuing this further in this paper.

\section{Alternative specifications}

The mixture model framework allows us quite easily to estimate alternative specifications that vary either the specification of household types or the determinants of mixing probabilities. Here we briefly discuss two specifications that have some a priori appeal but turn out to add relatively little explanatory power in our Danish dataset.

First, it is natural to think that some households might be able to compute the static benefits of refinancing while being unable to handle the more difficult issues associated with optionality and the volatility of interest rates. ${ }^{22}$ We might call such households staticheads (type $h=S$ ). For these households the threshold function is not the expression from ADL, but instead compares the fixed cost of refinancing, amortized over the life of a loan, with the after-tax interest saving. The resulting expression is:

$$
O_{S}\left(z_{i, t}\right)=\frac{f}{(1-\tau) m_{i, t}} \frac{1}{\left(\frac{1}{\rho}-\rho(1+\rho)^{T_{i, t}}\right)},
$$

where all parameters are as defined earlier.

When we replace levelheads with staticheads in our model, we find that the explanatory power of the model deteriorates and the fraction of staticheads is smaller than that of levelheads. The reason is that staticheads use a threshold that is too low, since it ignores the option value of delaying refinancing, and thus they tend to make errors of commission rather

\footnotetext{
${ }^{22}$ We thank Xavier Gabaix for suggesting that we consider households of this sort.
} 
than errors of omission. But as we have already noted, errors of commission are quite rare in our dataset.

Second, we consider the possibility that some households respond to a relatively crude signal of a refinancing opportunity, the issuance of a new mortgage bond with a coupon $2 \%$ or $3 \%$ below the coupon on the household's existing mortgage. Since Danish mortgage bonds are issued with coupons below market yields, a coupon spread of $2 \%$ or $3 \%$ does not imply a raw interest saving of this magnitude, but it is a discrete event that may attract the attention of less financially sophisticated households, in part through media coverage.

The issuance of a new bond with a coupon spread of $2 \%$ or $3 \%$ almost always coincides with large positive incentives, calculated using the ADL threshold. This means that we can specify either that the event increases the probability that a household is a levelhead, or that it increases the probability that woodhead households refinance; these specifications are approximately observationally equivalent because the event almost always occurs when it is rational to refinance.

When we include dummies for this event in the mixture model, allowing it to affect the probability that a household is a levelhead, we find some evidence of a lagged response to the event. As shown in the appendix, the model has a somewhat better fit to the refinancing spike shown in Figure 6 around an incentive of 1 , and the pseudo- $R^{2}$ increases to $16.6 \%$. However, the lag lengths are long, particularly for the $2 \%$ coupon spread, and demographic effects appear similar in this model to the model reported in Table 7. 


\section{Conclusion}

In this paper we have presented an analysis of sluggish mortgage refinancing behavior among Danish households. The Danish context is particularly advantageous for studying this type of household behavior because the Danish mortgage system places no restrictions on refinancing that does not involve cash-out, so households that pass up opportunities to substantially reduce their mortgage costs are not constrained, but are making mistakes in managing their finances. In addition, the Danish statistical system allows us to measure demographic and economic characteristics of households, and to use them to predict refinancing probabilities.

We distinguish between inattention (a reduced sensitivity to refinancing incentives) and inertia (a lower baseline refinancing probability of an inattentive household). We capture these phenomena using a mixture model of stylized household types, "levelheads" who refinance rationally and "woodheads" who refinance at a fixed rate. Demographic characteristics can affect both the proportion of levelheads in the demographic group, our measure of attention, and the refinancing probability of woodheads, our measure of residual inertia.

We find that inertia is not constant across demographic groups: many household characteristics move inertia and inattention in the same direction, so these attributes are positively correlated across households, although the correlation is not perfect. Younger, better educated, and higher-income households have less inertia and less inattention. Interestingly, financial wealth and housing wealth have opposite effects, with the least inertia and inattention among households whose housing wealth is high relative to their financial wealth. We also find suggestive evidence that inattention is a persistent characteristic at the household level, even after controlling for demographics, so that positive refinancing incentives induce refinancing by attentive households and lower the subsequent responsiveness of remaining mortgage borrowers.

Both our methodology and our findings have relevance beyond the context of this pa-

per. We believe that mixture models are a promising econometric method for estimat- 
ing the prevalence of behavioral biases in the population, and a useful alternative to the competing-risks proportional hazard framework of Deng, Quigley, and Van Order (2000) for modeling heterogeneous prepayment behavior. Our findings reinforce concerns that financial capabilities deteriorate late in life (Agarwal, Driscoll, Gabaix, and Laibson 2009) and that poorer households make worse financial decisions, contributing to inequality of wealth (Piketty 2014). This is particularly true because we estimate that refinancing mistakes have substantial costs during our sample period. Finally, our observations of cross-sectional variation in refinancing behavior are consistent with studies of other household financial mistakes in other countries (for example Campbell 2006 and Calvet, Campbell, and Sodini 2009b), suggesting that demographic characteristics of households can be used to estimate their financial capabilities across different countries and contexts. 


\section{References}

Abel, Andrew B., Janice C. Eberly, and Stavros Panageas, 2007, "Optimal Inattention to the Stock Market", American Economic Review: Papers and Proceedings 97, 244-249.

Abel, Andrew B., Janice C. Eberly, and Stavros Panageas, 2013, "Optimal Inattention to the Stock Market with Information Costs and Transactions Costs", Econometrica 81, $1455-1481$.

Agarwal, Sumit, John Driscoll, and David Laibson, 2013, "Optimal Mortgage Refinancing: A Closed Form Solution", Journal of Money, Credit, and Banking 45, 591-622.

Agarwal, Sumit, John Driscoll, Xavier Gabaix, and David Laibson, 2009, "The Age of Reason: Financial Decisions Over the Life Cycle and Implications for Regulation", Brookings Papers on Economic Activity 2, 51-101.

Agarwal, Sumit, Richard J. Rosen, and Vincent Yao, 2012, "Why Do Borrowers Make Mortgage Refinancing Mistakes?", working paper, Federal Reserve Bank of Chicago.

Agnew, Julie, Pierluigi Balduzzi, and Annika Sunden, 2003, "Portfolio Choice and Trading in a Large 401(k) Plan", American Economic Review 93, 193-215.

Alvarez, Fernando, Luigi Guiso, and Francesco Lippi, 2012, "Durable Consumption and Asset Management with Transaction and Observation Costs", American Economic Review 102, 2272-2300.

Alvarez, Fernando, Francesco Lippi, and Luigi Paciello, 2011, "Optimal Price Setting With Observation and Menu Costs", Quarterly Journal of Economics 126, 1909-1960.

Andersen, Steffen, John Y. Campbell, Kasper Meisner Nielsen, and Tarun Ramadorai, 2015, "Appendix to Inattention and Inertia in Household Finance", available online at authors' websites.

Archer, Wayne R., David C. Ling, and Gary A. McGill, 1996, "The Effect of Income and Collateral Constraints on Residential Mortgage Terminations", Regional Science and Urban Economics 26, 235-261.

Badarinza, Cristian, John Y. Campbell, and Tarun Ramadorai, 2015, "What Calls to ARMs? International Evidence on Interest Rates and the Choice of Adjustable Rate Mortgages," revision of NBER Working Paper No. 20408.

Bajo, Emanuele, Massimiliano Barbi, and Francesca Bartoli, 2014, "Financial Illiteracy and Mortgage Refinancing Decisions", unpublished paper, University of Bologna.

Bennett, Paul, Richard Peach, and Stavros Peristiani, 2001, "Structural Change in the Mortgage Market and the Propensity to Refinance", Journal of Money, Credit, and Banking 33, 955-975. 
Bhutta, Neil and Benjamin J. Keys, 2013, "Interest Rates and Equity Extraction During the Housing Boom", unpublished paper, Federal Reserve Board and University of Chicago.

Bilias, Yannis, Dimitris Georgarakos, and Michael Haliassos, 2010, "Portfolio Inertia and Stock Market Fluctuations", Journal of Money, Credit and Banking 42, 715-742.

Brueckner, Jan K. and James R. Follain, 1988, "The Rise and Fall of the ARM: An Econometric Analysis of Mortgage Choice," Review of Economics and Statistics 70, 93-102.

Brunnermeier, Markus K. and Stefan Nagel, 2008, "Do Wealth Fluctuations Generate TimeVarying Risk Aversion? Micro-Evidence on Individuals", American Economic Review $98,713-736$.

Bucks, Brian and Karen Pence, 2008, "Do Borrowers Know Their Mortgage Terms?", Journal of Urban Economics 64, 218-233.

Calvet, Laurent, John Y. Campbell, and Paolo Sodini, 2009a, "Fight or Flight? Portfolio Rebalancing by Individual Investors", Quarterly Journal of Economics 124, 301-348.

Calvet, Laurent, John Y. Campbell, and Paolo Sodini, 2009b, "Measuring the Financial Sophistication of Households", American Economic Review Papers and Proceedings 99, 393-398.

Campbell, John Y., 2006, "Household Finance", Journal of Finance 61, 1553-1604.

Campbell, John Y., 2013, "Mortgage Market Design", Review of Finance 17, 1-33.

Campbell, John Y. and Joao Cocco, 2003, "Household Risk Management and Optimal Mortgage Choice", Quarterly Journal of Economics 118, 1449-1494.

Campbell, John Y. and Joao Cocco, 2015, "A Model of Mortgage Default", forthcoming Journal of Finance.

Caplin, Andrew, Charles Freeman, and Joseph Tracy, 1997, "Collateral Damage: Refinancing Constraints and Regional Recessions", Journal of Money, Credit, and Banking 29, $496-516$.

Chen, Andrew and David Ling, 1989, "Optimal Mortgage Refinancing with Stochastic Interest Rates", AREUEA Journal 17, 278-99.

Chen, Hui, Michael Michaux, and Nikolai Roussanov, 2013, "Houses as ATMs? Mortgage Refinancing and Macroeconomic Uncertainty", unpublished paper, MIT, USC, and University of Pennsylvania.

Choi, James J., David Laibson, Brigitte Madrian, and Andrew Metrick, 2002, "Defined Contribution Pensions: Plan Rules, Participant Decisions, and the Path of Least Resistance", in James Poterba ed. Tax Policy and the Economy 16, 67-113. 
Choi, James J., David Laibson, Brigitte Madrian, and Andrew Metrick, 2004, "For Better or for Worse: Default Effects and 401(k) Savings Behavior", in David Wise ed. Perspectives on the Economics of Aging, University of Chicago Press.

DellaVigna, Stefano, and Joshua M. Pollet, 2007, "Demographics and Industry Returns", American Economic Review 97, 1667-1702.

Deng, Yongheng and John M. Quigley, 2012, "Woodhead Behavior and the Pricing of Residential Mortgages", unpublished paper, National University of Singapore and University of California Berkeley.

Deng, Yongheng, John M. Quigley and Robert Van Order, 2000, "Mortgage Terminations, Heterogeneity, and the Exercise of Mortgage Options", Econometrica 68, 275-307.

Dhillon, Upinder S., James D. Shilling, and C.F. Sirmans, 1987, "Choosing Between Fixed and Adjustable Rate Mortgages: Note", Journal of Money, Credit, and Banking 19, 260-267.

Duffie, Darrell, and Tong-sheng Sun, 1990, "Transactions Costs and Portfolio Choice in a Discrete-Continuous-Time Setting", Journal of Economic Dynamics and Control 14, $35-51$.

El-Gamal, Mahmoud A. and David M. Grether, 1995, "Are People Bayesian? Uncovering Behavioral Strategies", Journal of the American Statistical Association 90, 1137-1145.

Gabaix, Xavier, Arvind Krishnamurthy, and Olivier Vigneron, 2007, "Limits of Arbitrage: Theory and Evidence from the Mortgage-Backed Securities Market", Journal of Finance $62,557-595$.

Gabaix, Xavier and David I. Laibson, 2002, "The 6D Bias and the Equity-Premium Puzzle," in Ben S. Bernanke and Kenneth S. Rogoff eds. NBER Macroeconomics Annual 2001, MIT Press, Cambridge, MA, 257-312.

Gyntelberg, J., Kjeldsen, K., Baekmand Nielsen, M., and Persson, M., 2012, "The 2008 Financial Crisis and the Danish Mortgage Market", in A. Bardhan, R.H. Edelstein, and C.A. Kroll eds. Global Housing Markets: Crises, Policies, and Institutions, John Wiley, 53-68.

Hall, Arden, 2000, "Controlling for Burnout in Estimating Mortgage Prepayment Models", Journal of Housing Economics 9, 215-232.

Johnson, Kathleen W. and Geng Li, 2014, "Are Adjustable-Rate Mortgage Borrowers Borrowing Constrained?," Real Estate Economics 42, 457-471.

Harrison, Glenn W. and E. Elisabet Rutström, 2009, "Expected Utility Theory and Prospect Theory: One Wedding and a Decent Funeral," Experimental Economics 12, 133-158. 
Johnson, Eric, Stephan Meier, and Olivier Toubia, 2015, "Leaving Money on the Kitchen Table: Exploring Sluggish Mortgage Refinancing Using Administrative Data, Surveys, and Field Experiments", unpublished paper, Columbia Business School.

Kang, Pan and Stavros A. Zenios, 1992, "Complete Prepayment Models for MBS", Management Science 38, 1665-1685.

Keys, Benjamin J., Devin G. Pope, and Jaren C. Pope, 2014, "Failure to Refinance", NBER Working Paper No. 20401.

Khandani, Amir E., Andrew W. Lo, and Robert C. Merton, 2013, "Systemic Risk and the Refinancing Ratchet Effect", Journal of Financial Economics 108, 29-45.

Koijen, Ralph S.J., Van Hemert, Otto and Stijn Van Nieuwerburgh, 2009, "Mortgage Timing," Journal of Financial Economics 93, 292-324.

LaCour-Little, Michael, 1999, "Another Look at the Role of Borrower Characteristics in Predicting Mortgage Prepayments", Journal of Housing Research 10, 45-60.

Lea, M., 2011, "Alternative Forms of Mortgage Finance: What Can We Learn from Other Countries?" in N. Retsinas and E. Belsky eds., Moving Forward: The Future of Consumer Credit and Mortgage Finance, Joint Center for Housing Studies, Harvard University, Cambridge, MA, and Brookings Institution Press, Washington, DC, 118-149.

Luce, R. Duncan, 1959, Individual Choice Behavior: A Theoretical Analysis, Wiley, New York, NY.

Madrian, Brigitte and Dennis Shea, 2001, "The Power of Suggestion: Inertia in 401(k) Participation and Savings Behavior", Quarterly Journal of Economics 66, 1149-1188.

McConnell, John J., and Manoj Singh, 1994, "Rational Prepayments and the Valuation of Collateralized Mortgage Obligations", Journal of Finance 49, 891-921.

McLachlan, Geoffrey and David Peel, 2000, Finite mixture models, Wiley, New York, NY.

Miles, David, 2004, The UK Mortgage Market: Taking a Longer-term View, HM Treasury, London, UK.

Moscarini, Giuseppe, 2004, "Limited Information Capacity as a Source of Inertia", Journal of Economic Dynamics and Control 28, 2003-2035.

Pearson, Karl, 1894, "Contributions to the Mathematical Theory of Evolution", Philosophical Transactions of the Royal Society of London A, 71-110.

Piketty, Thomas, 2014, Capital in the 21st Century, Harvard University Press, Cambridge, MA. 
Reis, Ricardo, 2006, "Inattentive Consumers", Journal of Monetary Economics 53, 17611800.

Schwartz, Allie, 2006, "Household Refinancing Behavior in Fixed-Rate Mortgages", unpublished paper, Harvard University.

Schwartz, Eduardo S., and Walter N. Torous, 1989, "Prepayment and the Valuation of Mortgage-Backed Securities", Journal of Finance 44, 375-392.

Sims, Christopher A., 2003, "Implications of Rational Inattention", Journal of Monetary Economics 50, 665-690.

Stanton, Richard, 1995, "Rational Prepayment and the Valuation of Mortgage-Backed Securities", Review of Financial Studies 8, 677-708.

Tracy, Joseph and Joshua Wright, 2012, "Payment Changes and Default Risk: The Impact of Refinancing on Expected Credit Losses", Federal Reserve Bank of New York Staff Report No. 562.

Veronesi, Pietro, 2010, Fixed Income Securities: Valuation, Risk, and Risk Management, John Wiley \& Sons, Hoboken, NJ.

Woodford, Michael, 2009, "Information-Constrained State-Dependent Pricing", Journal of Monetary Economics 56, Supplement, S100-S124.

Woodward, Susan E., and Robert E. Hall, 2010, "Consumer Confusion in the Mortgage Market: Evidence of Less Than a Perfectly Transparent and Competitive Market", American Economic Review 100, 511-515.

Woodward, Susan E. and Robert E. Hall, 2012, "Diagnosing Consumer Confusion and Sub-Optimal Shopping Effort: Theory and Mortgage Market Evidence", American Economic Review 102, 3249-3276.

Zandi, Mark and Cristian deRitis, 2011, "Improved HARP Will Expand Refinancing, Boost Recovery", unpublished report, Moody's Analytics.

Zhu, Jun, 2012, "Refinance and Mortgage Default: An Empirical Analysis of the HARP's Impact on Default Rates", unpublished paper, Freddie Mac. 


\section{Table 1: Characteristics of Danish Fixed Rate Mortgages}

The average characteristics in Panel A (B) are calculated using mortgages taken by all households in Denmark with an unchanging number of members, and with a single fixed rate mortgage at the beginning of 2010 and 2011. The first five columns show the statistics broken out by the annual coupon rate on these mortgages, and the final column in each panel shows the statistics across all mortgages in each of the periods. The rows show, in order, the number of observations; the fraction refinancing, i.e. the fraction of households who did not move house and refinanced their pre-existing mortgage; the fraction refinancing to adjustable rate mortgages (ARM); the fraction refinancing to fixed rate mortgages (FRM); the principal remaining in Danish Kroner, i.e., the outstanding principal on the mortgage; the years remaining before the mortgage matures; and the loan-to-value (LTV) ratio calculated by the mortgage bank.

Initial \# of observations

Fraction refinancing

Fraction refinancing to ARM

Fraction refinancing to FRM

Principal remaining (Million DKK)

Years remaining on mortgage

Loan-to-value (LTV) ratio

Initial \# of observations

Fraction refinancing

Fraction refinancing to ARM

Fraction refinancing to FRM

Principal remaining (Million DKK)

Years remaining on mortgage

Loan-to-value (LTV) ratio

DKK)

\begin{tabular}{cccccc} 
3\% Coupon & 4\% Coupon & 5\% Coupon & 6\% Coupon & $>6 \%$ Coupon & Total \\
\hline 8,054 & 79,929 & 141,610 & 44,590 & 7,515 & 281,698 \\
0.039 & 0.050 & 0.203 & 0.556 & 0.437 & 0.217 \\
0.013 & 0.024 & 0.108 & 0.218 & 0.153 & 0.100 \\
0.026 & 0.026 & 0.095 & 0.338 & 0.284 & 0.117 \\
0.394 & 0.888 & 0.947 & 0.946 & 0.598 & 0.905 \\
7.849 & 21.425 & 24.552 & 25.371 & 22.281 & 23.256 \\
0.242 & 0.506 & 0.595 & 0.640 & 0.462 & 0.563
\end{tabular}

Panel B: 2011

\begin{tabular}{cccccc}
$3 \%$ Coupon & 4\% Coupon & 5\% Coupon & 6\% Coupon & $>6 \%$ Coupon & Total \\
\hline 10,168 & 110,709 & 125,369 & 21,205 & 4,442 & 271,893 \\
0.031 & 0.041 & 0.114 & 0.159 & 0.117 & 0.085 \\
0.012 & 0.019 & 0.060 & 0.062 & 0.045 & 0.037 \\
0.018 & 0.021 & 0.053 & 0.097 & 0.095 & 0.048 \\
0.479 & 0.978 & 0.883 & 0.591 & 0.321 & 0.875 \\
8.662 & 22.542 & 23.686 & 21.785 & 17.389 & 22.407 \\
0.290 & 0.557 & 0.564 & 0.486 & 0.299 & 0.541
\end{tabular}




\section{Table 2: Differences in Household Characteristics: Refinancing and Non-Refinancing Households}

The first column shows the average of each of the characteristics reported in the rows, pooled across 2010 and 2011 for our entire sample. Columns 2 to 7 report the difference of means between refinancing and non-refinancing households, with a negative value indicating a lower mean for refinancing households. Differences are reported either unconditionally across the entire sample (Column “All”); conditional on sub-periods (Columns “2010” and “2011”); or conditional on other household characteristics (Columns “Educated“, "Married”, “Wealthy”). "Educated" households are defined as the upper $25 \%$ of the sample population. "Wealthy" households are those in the upper $25 \%$ of net financial wealth in the sample. The rows describe the characteristics; single households (male or female) have only one adult living at the address, and represent 13\% of the entire sample. "Married" households have two legally bound adults (including registered partnership of same-sex couples). "Children in family" means children are resident in the household. "Immigrant” takes the value of one if there is an immigrant in the household. "No educational information" indicates no information provided about this attribute. "Financially literate" takes the value of one if a member of the household has a degree in finance, or has had professional financial industry training. "Family financially literate" indicates if (non-household-resident) parents, siblings, in-laws, or children of the household are financially literate. "Getting married" indicates a change in marital status over the sample period. "Change to health" indicates when a member of the household spent more than 5 days in hospital within the last 12 months, and less than 5 days in hospital in the prior year. "Having children" indicates when households had a child within the last 12 months. "Rank of Age" is the rank of the age of the oldest person living in the household. "Rank of Education" is the rank of the best educated individual in the household. "Rank of Income (financial wealth, housing assets)" is the rank of the total income (financial wealth, housing assets) of the household. All ranks are computed each year across all households in the sample. Rank variables are normalized such that they take values between -0.5 and 0.5 . ***,**, and * indicate coefficients that are significant at the one, five, and ten percent level by standard t-tests, respectively.

Single male household

Single female household

Married household

Children in family

Immigrant

No educational information

Financially literate

Family financially literate

Getting married

Change to health

Having children

Rank of age

Rank of education

Rank of income

Rank of financial wealth

Rank of housing value

Region North Jutland

Region Middle Jutland

Region Southern Denmark

Region Zealand

Region Copenhagen

\# of observations

\begin{tabular}{r} 
\\
Average \\
\hline 0.128 \\
0.124 \\
0.638 \\
0.406 \\
0.072 \\
0.006 \\
0.046 \\
0.129 \\
0.010 \\
0.036 \\
0.042 \\
0.015 \\
0.004 \\
0.008 \\
0.009 \\
0.010 \\
0.124 \\
0.241 \\
0.228 \\
0.187 \\
0.220 \\
$2,146,395$
\end{tabular}

Difference between Refinancing and Non-Refinancing Households

\begin{tabular}{|c|c|c|c|c|c|}
\hline All & 2010 & 2011 & Educated & Married & Wealthy \\
\hline$-0.041^{* * * *}$ & $-0.034^{* * *}$ & $-0.030^{* * * *}$ & $-0.015^{* * *}$ & & $-0.027^{* * *}$ \\
\hline$-0.029^{* * *}$ & $-0.029^{* * *}$ & $-0.026^{* * *}$ & $-0.022^{* * *}$ & & $-0.015^{* * *}$ \\
\hline $0.024^{* * *}$ & $0.021^{* * *}$ & $0.025^{* * *}$ & 0.004 & & $0.031^{* * *}$ \\
\hline $0.102^{* * *}$ & $0.108^{* * *}$ & $0.079^{* * *}$ & $0.079^{* * *}$ & $0.095^{* * *}$ & $0.064^{* * *}$ \\
\hline-0.001 & 0.000 & -0.001 & $-0.006^{* * *}$ & $-0.004^{* * *}$ & 0.002 \\
\hline$-0.003^{* * *}$ & $-0.002^{* * *}$ & $-0.003^{* * *}$ & & $0.000^{* * *}$ & $-0.002^{* * *}$ \\
\hline $0.006^{* * *}$ & $0.004^{* * *}$ & $0.011^{* * *}$ & $0.011^{* * *}$ & $0.004^{* * *}$ & $0.020^{* * *}$ \\
\hline $0.016^{* * *}$ & $0.015^{* * *}$ & $0.021^{* * *}$ & $0.023^{* * *}$ & $0.011^{* * *}$ & $0.034^{* * *}$ \\
\hline $0.009^{* * *}$ & $0.010^{* * *}$ & $0.006^{* * *}$ & $0.010^{* * *}$ & & $0.004^{* * *}$ \\
\hline$-0.004^{* * *}$ & $-0.002^{* * *}$ & $-0.006^{* * *}$ & -0.001 & $-0.005^{* * *}$ & $-0.006^{* * *}$ \\
\hline $0.032^{* * *}$ & $0.033^{* * *}$ & $0.026^{* * *}$ & $0.036^{* * *}$ & $0.028^{* * *}$ & $0.019^{* * *}$ \\
\hline$-0.087^{* * *}$ & $-0.098^{* * *}$ & $-0.070^{* * *}$ & $-0.079^{* * *}$ & $-0.075^{* * *}$ & $-0.047^{* * *}$ \\
\hline $0.027^{* * *}$ & $0.029^{* * * *}$ & $0.024^{* * *}$ & 0.000 & $0.017^{* * *}$ & $0.031^{* * *}$ \\
\hline $0.056^{* * *}$ & $0.058^{* * *}$ & $0.049^{* * *}$ & $0.027^{* * *}$ & $0.033^{* * *}$ & $0.049^{* * *}$ \\
\hline$-0.094^{* * *}$ & $-0.102^{* * *}$ & $-0.082^{* * *}$ & $-0.100^{* * *}$ & $-0.909^{* * *}$ & $-0.003^{* * *}$ \\
\hline $0.029^{* * *}$ & $0.028^{* * *}$ & $0.027^{* * *}$ & $0.011^{* * *}$ & $0.019^{* * *}$ & $0.060^{* * *}$ \\
\hline 0.000 & $0.004^{* * *}$ & $-0.006^{* * *}$ & $0.004^{* * *}$ & 0.000 & $-0.016^{* * *}$ \\
\hline $0.023^{* * *}$ & $0.026^{* * *}$ & $0.015^{* * *}$ & $0.023^{* * *}$ & $0.021^{* * *}$ & $0.015^{* * *}$ \\
\hline 0.002 & $-0.004^{* * *}$ & $0.018^{* * *}$ & $-0.003^{* * *}$ & -0.001 & $-0.020^{* * *}$ \\
\hline$-0.015^{* * *}$ & $-0.012^{* * *}$ & $-0.023^{* * *}$ & $-0.012^{* * *}$ & $-0.014^{* * *}$ & $-0.004^{* * *}$ \\
\hline$-0.011^{* * *}$ & $-0.013^{* * *}$ & -0.004 & $-0.012^{* * *}$ & $-0.006^{* * *}$ & $0.026^{* * *}$ \\
\hline 2,146,395 & $1,067,776$ & $1,078,619$ & 792,584 & $1,442,780$ & 566,032 \\
\hline
\end{tabular}




\section{Table 3: Refinancing and Incentives}

The percentiles of the distribution reported in the column headings are calculated across our entire sample of Danish households, pooling data over 2010 and 2011, as well as separately by year. The blocks of statistics refer to the interest rate spread in percentage points (defined as the coupon rate on the old mortgage less the yield on a newly available mortgage of roughly the same maturity); the threshold level above which refinancing is sensible, taking into account the option value of waiting, reported in percentage points, and calculated using the closed form solution in the Agarwal et al. (2013) formula; and the total incentive in percentage points, measured as the interest rate spread less the computed threshold level. Within each block of statistics, percentiles are calculated for all households separately for each variable, and separately for the sub-populations of refinancing and non-refinancing households. To preserve confidentiality, percentiles are calculated using 5 nearest observations to the percentile point.

\begin{tabular}{|c|c|c|c|c|c|c|c|}
\hline & $1 \%$ & $5 \%$ & $25 \%$ & Median & $75 \%$ & $95 \%$ & $99 \%$ \\
\hline & & \multicolumn{6}{|c|}{ Interest Rate Spread in Percentage Points } \\
\hline All & -1.10 & -1.01 & -0.16 & 0.23 & 0.84 & 1.90 & 2.94 \\
\hline 2010 & -1.01 & -1.01 & -0.18 & 0.19 & 0.82 & 1.82 & 2.82 \\
\hline \multirow[t]{2}{*}{2011} & -1.10 & -1.10 & -0.16 & 0.45 & 0.90 & 1.90 & 3.24 \\
\hline & & \multicolumn{6}{|c|}{ Threshold Level in Percentage Points } \\
\hline All & 0.51 & 0.61 & 0.83 & 1.08 & 1.50 & 2.96 & 6.92 \\
\hline 2010 & 0.50 & 0.60 & 0.81 & 1.06 & 1.47 & 2.83 & 5.93 \\
\hline \multirow[t]{2}{*}{2011} & 0.52 & 0.62 & 0.84 & 1.10 & 1.52 & 3.08 & 8.13 \\
\hline & & \multicolumn{6}{|c|}{ Incentives in Percentage Points } \\
\hline All & -5.98 & -2.66 & -1.49 & -0.89 & -0.25 & 0.49 & 1.18 \\
\hline 2010 & -5.11 & -2.59 & -1.43 & -0.85 & -0.22 & 0.53 & 1.18 \\
\hline 2011 & -7.09 & -2.74 & -1.54 & -0.93 & -0.29 & 0.44 & 1.17 \\
\hline
\end{tabular}




\section{Table 4: Errors of Commission and Omission}

This table shows the incidence of errors of commission and omission, and the characteristics of households who commit errors of commission (refinancing when it is suboptimal), and errors of omission (not refinancing when it is optimal). We calculate the levels of incentives to engage in refinancing using the interest rate spread between the old and new mortgages less the Agarwal et al. (2013) formula which quantifies the option-value of waiting, and we use these computed incentives (plus cutoff levels to control for noise in estimation) to classify errors. Each column shows cost estimates corresponding to the cutoff levels shown in the column header. For example, a cutoff level of 0 (0.25) corresponds to the interest rate spread being exactly equal to the computed Agarwal et al. (2013) threshold level (exceeding the Agarwal et al. (2013) threshold level by 25 basis points). Errors of commission (omission) which correspond to each cutoff are computed as the percentage of household-quarters with incentives below (above) the negative of the cutoff (the cutoff), who refinance (do not refinance). Columns report the incidence of errors of commission and omission for cutoff levels ranging from 0 to 2 percentage points.

\section{Level of Cutoff}

\# Observations (Incentives <-Cutoff)

\# Observations, refinancing

\# Observations, cash out or extend maturity

\# Observations, errors of commission

Fraction with error of commission

\# Observations (Incentives > Cutoff)

\# Observations, errors of omission

Fraction with error of omission

\begin{tabular}{rrrrrrr}
0 & 0.25 & 0.5 & 0.75 & 1 & 1.5 & 2 \\
\hline $1,688,215$ & $1,475,545$ & $1,278,737$ & 751,439 & 362,251 & 137,457 & 137,457 \\
37,297 & 28,294 & 22,095 & 14,340 & 7,983 & 2,919 & 1,014 \\
15,743 & 12,224 & 9,715 & 7,356 & 4,878 & 1,921 & 791 \\
21,554 & 16,070 & 12,380 & 6,984 & 3,105 & 998 & 223 \\
0.013 & 0.011 & 0.010 & 0.009 & 0.009 & 0.007 & 0.002 \\
& & & & & & \\
458,180 & 252,336 & 152,097 & 100,844 & 61,309 & 17,434 & 6,287 \\
411,015 & 220,084 & 130,389 & 83,668 & 49,456 & 15,749 & 5,746 \\
0.897 & 0.872 & 0.857 & 0.830 & 0.807 & 0.903 & 0.914
\end{tabular}




\section{Table 5: Household Characteristics and Refinancing Errors.}

This table reports the mean difference for each demographic characteristic between refinancing and non-refinancing households who commit errors of commission and omission for cutoff levels of 0 and 25 basis points. We calculate the levels of incentives to engage in refinancing using the interest rate spread between the old and new mortgages less the Agarwal et al. (2013) formula which quantifies the option-value of waiting, and we use these computed incentives (plus cutoff levels to control for noise in estimation) to classify errors. Positive (negative) numbers under columns marked "Increases in Errors of Commission" signify demographic characteristics which are associated with shifts of householdquarters into (out of) such errors, and similarly positive (negative) numbers under columns marked "Reductions in Errors of Commission" signify demographic characteristics which are associated with shifts of household-quarters out of (into) such errors. $* * *, * *$, and * indicate coefficients that are significant at the one, five, and ten percent level by standard t-tests, respectively.

\begin{tabular}{|c|c|c|c|}
\hline \multicolumn{2}{|c|}{ Cutoff $=0$} & \multicolumn{2}{|c|}{ Cutoff $=0.25$} \\
\hline $\begin{array}{l}\text { Increases in Errors of } \\
\text { Commission }\end{array}$ & $\begin{array}{l}\text { Reductions in Errors } \\
\text { of Omission }\end{array}$ & $\begin{array}{l}\text { Increases in Errors } \\
\text { of Commission }\end{array}$ & $\begin{array}{c}\text { Reductions in Errors of } \\
\text { Omission }\end{array}$ \\
\hline $1,688,215$ & 458,180 & $1,475,545$ & 252,336 \\
\hline$-0.017^{* * *}$ & $-0.025^{* * *}$ & $-0.020^{* * *}$ & $-0.041^{* * *}$ \\
\hline$-0.015^{* * *}$ & $-0.020^{* * *}$ & $-0.017^{* * *}$ & $-0.031^{* * *}$ \\
\hline $0.002^{* * *}$ & $0.008^{* * *}$ & $0.011^{* * *}$ & $0.028^{* * *}$ \\
\hline $0.055^{* * *}$ & $0.077^{* * *}$ & $0.064^{* * *}$ & $0.115^{* * *}$ \\
\hline$-0.005^{* * *}$ & $-0.006^{* * *}$ & $-0.006^{* * *}$ & $-0.006^{* * *}$ \\
\hline $0.002^{* * *}$ & $0.008^{* * *}$ & $0.002^{*}$ & $0.009^{* * *}$ \\
\hline $0.007^{* * *}$ & $0.019^{* * *}$ & $0.008^{* * *}$ & $0.023^{* * *}$ \\
\hline$-0.003^{* * *}$ & $-0.002^{* * *}$ & $-0.003^{* * *}$ & $-0.004^{* * *}$ \\
\hline $0.007^{* * *}$ & $0.009^{* * * *}$ & $0.007^{* * *}$ & $0.010^{* * *}$ \\
\hline$-0.003^{* * *}$ & $-0.004^{* * *}$ & $-0.004^{* * *}$ & $-0.006^{* * *}$ \\
\hline $0.025^{* * *}$ & $0.029^{* * *}$ & $0.026^{* * *}$ & $0.035^{* * *}$ \\
\hline$-0.062^{* * *}$ & $-0.080^{* * *}$ & $-0.063^{* * *}$ & $-0.105^{* * *}$ \\
\hline $0.003^{* * *}$ & $0.028^{* * *}$ & $0.006^{* * *}$ & $0.046^{* * *}$ \\
\hline $0.018^{* * *}$ & $0.045^{* * *}$ & $0.025^{* * *}$ & $0.072^{* * *}$ \\
\hline$-0.098^{* * *}$ & $-0.073^{* * *}$ & $-0.104^{* * *}$ & $-0.087^{* * *}$ \\
\hline $0.005^{* * *}$ & $0.012^{* * *}$ & $0.016^{* * *}$ & $0.028^{* * *}$ \\
\hline $0.004^{* *}$ & $0.008^{* * *}$ & -0.003 & $0.007^{* * *}$ \\
\hline $0.019^{* * *}$ & $0.032^{* * *}$ & $0.014^{* * *}$ & $0.035^{* * *}$ \\
\hline $0.018^{* * *}$ & 0.001 & $0.017^{* * *}$ & $-0.005^{* *}$ \\
\hline$-0.018^{* * *}$ & $-0.020^{* * *}$ & $-0.014^{* * *}$ & $-0.014^{* * *}$ \\
\hline$-0.022^{* * *}$ & $-0.021^{* * *}$ & $-0.014^{* * *}$ & $-0.022^{* * *}$ \\
\hline
\end{tabular}




\section{Table 6: Costs of Errors of Omission}

This table estimates the costs of errors of omission. We calculate the levels of incentives to engage in refinancing using the interest rate spread between the old and new mortgages less the Agarwal et al. (2013) formula which quantifies the option-value of waiting, and we use these computed incentives (minus cutoff levels to control for noise in estimation) to classify errors. Each column shows cost estimates corresponding to the cutoff levels shown in the column header. For example, a cutoff level of 0 (0.25) corresponds to the interest rate spread being exactly equal to the computed Agarwal et al. (2013) threshold level (exceeding the Agarwal et al. (2013) threshold level by 25 basis points). Errors of omission occur for household-quarters with incentives above the cutoff, in which refinancing does not occur. The panel shows the cost of errors of omission calculated as the foregone annual interest saving (as a percentage of the outstanding mortgage balance) less the amortized fixed cost of refinancing given the available interest rates in each quarter of 2010 and 2011.

\section{Level of Cutoff}

\begin{tabular}{lccccccc}
\multicolumn{7}{c}{0} & \multicolumn{2}{c}{0.25} & 0.5 & 0.75 & 1 & 1.5 & 2.0 \\
\hline All & \multicolumn{7}{c}{ Cost of errors of omission as \% of outstanding mortgage } \\
2010 & $1.48 \%$ & $1.86 \%$ & $2.09 \%$ & $2.12 \%$ & $2.50 \%$ & $3.33 \%$ & $4.01 \%$ \\
2011 & $1.42 \%$ & $1.77 \%$ & $1.99 \%$ & $2.49 \%$ & $2.31 \%$ & $3.15 \%$ & $3.70 \%$ \\
\multicolumn{7}{c}{ Cost of errors of omission as \% of all outstanding mortgages } \\
All & $1.57 \%$ & $2.02 \%$ & $2.27 \%$ & $2.26 \%$ & $2.87 \%$ & $3.54 \%$ & $4.34 \%$ \\
2010 & $0.36 \%$ & $0.26 \%$ & $0.21 \%$ & $0.15 \%$ & $0.12 \%$ & $0.04 \%$ & $0.02 \%$ \\
2011 & $0.42 \%$ & $0.31 \%$ & $0.24 \%$ & $0.18 \%$ & $0.08 \%$ & $0.04 \%$ & $0.01 \%$ \\
& $0.29 \%$ & $0.21 \%$ & $0.17 \%$ & $0.12 \%$ & $0.10 \%$ & $0.04 \%$ & $0.02 \%$
\end{tabular}


Table 7: Mixture Models

In these specifications, the dependent variable takes the value of 1 for a refinancing in a given quarter, and 0 otherwise. We estimate these specifications using all households in Denmark with an unchanging number of members, with a fixed rate mortgage in 2010 and 2011. In column 1 we estimate a simple baseline model with no demographics, in which we measure attention as the reaction to incentives computed as the interest rate spread between old and new mortgages less the Agarwal et al. (2013) function which quantifies the option value of waiting. Columns 2 and 3 estimate two separate specifications in which successively the woodhead refinancing probability and the probability of being a levelhead are allowed to depend on demographics as well as the dummies capturing issuing and current quarters, and mortgage issuers. Columns 4 and 5 present estimates from a mixture model in which both the woodhead refinancing probability and the probability of being a levelhead are allowed to depend on demographics and the above dummies. As before these models include non-linear transformations, $\mathrm{f}(\mathrm{x})$, of several of the rank control variables in addition to their levels, where $\mathrm{f}(\mathrm{x})=\sqrt{2} x^{2}$. Pseudo $\mathrm{R}^{2}$ is calculated using the formula $\mathrm{R}^{2}=1-\mathrm{L}_{1} / \mathrm{L}_{0}$, where $\mathrm{L}_{1}$ is the log likelihood from the given model and $\mathrm{L}_{0}$ is the log likelihood from a model including only woodheads with a constant refinancing probability. ***,**, and * indicate coefficients that are significant at the one, five, and ten percent level, respectively, using standard errors clustered at the level of households.

Single male household
Single female household
Married household
Children in family
Immigrant
Financially literate
Family financially literate
No education information
Getting married
Change to health
Having children
Region of Northern Jutland
Region of Middle Jutland
Region of Southern Denmark
Region of Zealand
Demeaned rank of:
Age
Length of education
Income
Financial wealth
Housing wealth

Non-linear transformation $f(x), x$ is the demeaned rank of: Age

Length of education

Income

Financial wealth

Housing wealth

Intercept: Woodhead Refinancing Probability

Intercept: Response of Levelheads

Intercept: Proportion of Levelheads

Issuing Quarter Dummies

Current Quarter Dummies

Mortgage Issuer Dummies

Pseudo $\mathrm{R}^{2}$

Log Likelihood

Observations

Baseline
Model

\begin{tabular}{|c|c|c|c|}
\hline $\begin{array}{l}\text { Woodhead } \\
\text { Refinancing } \\
\text { Probability }\end{array}$ & $\begin{array}{c}\text { Probability } \\
\text { of } \\
\text { Levelhead }\end{array}$ & $\begin{array}{l}\text { Woodhead } \\
\text { Refinancing } \\
\text { Probability }\end{array}$ & $\begin{array}{c}\text { Probability } \\
\text { of } \\
\text { Levelhead }\end{array}$ \\
\hline $0.065^{* *}$ & $0.177^{* * *}$ & -0.044 & $0.187^{* * *}$ \\
\hline $0.166^{* * *}$ & $0.192^{* * *}$ & $0.108^{* * *}$ & $0.158^{* * *}$ \\
\hline $0.069^{* * *}$ & $0.025^{*}$ & $0.075^{* * *}$ & 0.001 \\
\hline$-0.030^{*}$ & $-0.064^{* * *}$ & $-0.085^{* * *}$ & $-0.051^{* * *}$ \\
\hline$-0.215^{* * *}$ & $-0.142^{* * *}$ & $-0.193^{* * *}$ & $-0.091^{* * *}$ \\
\hline $0.119^{* * *}$ & $0.103^{* * *}$ & $0.096^{* *}$ & $0.097^{* * *}$ \\
\hline $0.062^{* * *}$ & $0.063^{* * *}$ & 0.046 & $0.055^{* * *}$ \\
\hline$-0.376^{* * *}$ & $-0.250^{* * *}$ & $-0.501^{* * *}$ & -0.107 \\
\hline $0.250^{* * *}$ & $0.183^{* * *}$ & $0.362^{* * *}$ & $0.094^{* *}$ \\
\hline 0.005 & -0.008 & -0.062 & -0.008 \\
\hline $0.196^{* * *}$ & $0.132^{* * *}$ & $0.242^{* * *}$ & $0.067^{* * *}$ \\
\hline $0.237^{* * *}$ & $0.249^{* * *}$ & $0.084^{* * *}$ & $0.272^{* * *}$ \\
\hline $0.290^{* * *}$ & $0.291^{* * *}$ & $0.141^{* * *}$ & $0.293^{* * *}$ \\
\hline $0.255^{* * *}$ & $0.207^{* * *}$ & $0.228^{* * *}$ & $0.146^{* * *}$ \\
\hline-0.015 & -0.012 & -0.046 & 0.003 \\
\hline$-0.447^{* * *}$ & $-0.373^{* * *}$ & $-0.358^{* * *}$ & $-0.339^{* * *}$ \\
\hline 0.037 & $0.076^{* * *}$ & -0.041 & $0.117^{* * *}$ \\
\hline 0.026 & $0.090^{* * *}$ & $-0.161^{* * *}$ & $0.212^{* * *}$ \\
\hline$-1.300^{* * *}$ & $-0.660^{* * *}$ & $-1.438^{* * *}$ & $-0.206^{* * *}$ \\
\hline $0.652^{* * *}$ & $0.263^{* * *}$ & $0.510^{* * *}$ & $0.156^{* * *}$ \\
\hline
\end{tabular}

\begin{tabular}{|c|c|c|c|c|}
\hline & $\begin{array}{c}0.876^{* * *} \\
-0.663^{* * *} \\
-0.365^{* * *} \\
0.138^{* * *} \\
-0.144^{* * *}\end{array}$ & $\begin{array}{c}0.807^{* * *} \\
-0.516^{* * *} \\
-0.367^{* * *} \\
0.300^{* * *} \\
0.178^{* * *}\end{array}$ & $\begin{array}{c}1.023^{* * *} \\
-0.672^{* * *} \\
-0.357^{* * *} \\
0.019^{* * *} \\
-0.163^{* * *}\end{array}$ & $\begin{array}{c}0.507^{* * *} \\
-0.312^{\text {***}} \\
-0.346^{\text {***}} \\
0.312^{\text {***}} \\
0.182^{\text {***}}\end{array}$ \\
\hline $\begin{array}{c}-4.655^{* * *} \\
0.940^{* * *} \\
-1.752^{* * *}\end{array}$ & $\begin{array}{l}-4.540^{* * *} \\
1.193^{* * *} \\
-2.166^{* * *}\end{array}$ & $\begin{array}{c}-4.882^{* * *} \\
0.798^{* * *} \\
-2.317^{* * *}\end{array}$ & $\begin{array}{r}-5 . \\
1 . \\
-2 .\end{array}$ & \\
\hline $\begin{array}{l}\text { No } \\
\text { No } \\
\text { No }\end{array}$ & $\begin{array}{l}\text { Yes } \\
\text { Yes } \\
\text { Yes }\end{array}$ & $\begin{array}{l}\text { Yes } \\
\text { Yes } \\
\text { Yes }\end{array}$ & & \\
\hline $\begin{array}{c}0.097 \\
-319,393.4 \\
2,146,395\end{array}$ & $\begin{array}{c}0.127 \\
-308,685.8 \\
2,146,395\end{array}$ & $\begin{array}{c}0.151 \\
-300,244.6 \\
2,146,395\end{array}$ & $\begin{array}{r}0 \\
-29 \\
2,1\end{array}$ & 8.3 \\
\hline
\end{tabular}




\section{Figure 1: Baseline Mixture Model}

This figure plots refinancing probabilities from the baseline mixture model estimated in Table 7 column 1 with homogeneous levelheads and woodheads. The solid line in the top panel of the figure shows the observed refinancing probability by incentive levels. The remaining lines show the model-predicted refinancing probabilities; (i) for woodheads (short dash and dot), (ii) for levelheads (long dash and dot), and finally (iii) the model predicted refinancing probability (long dash), which is the weighted average refinancing probability of woodheads and levelheads.

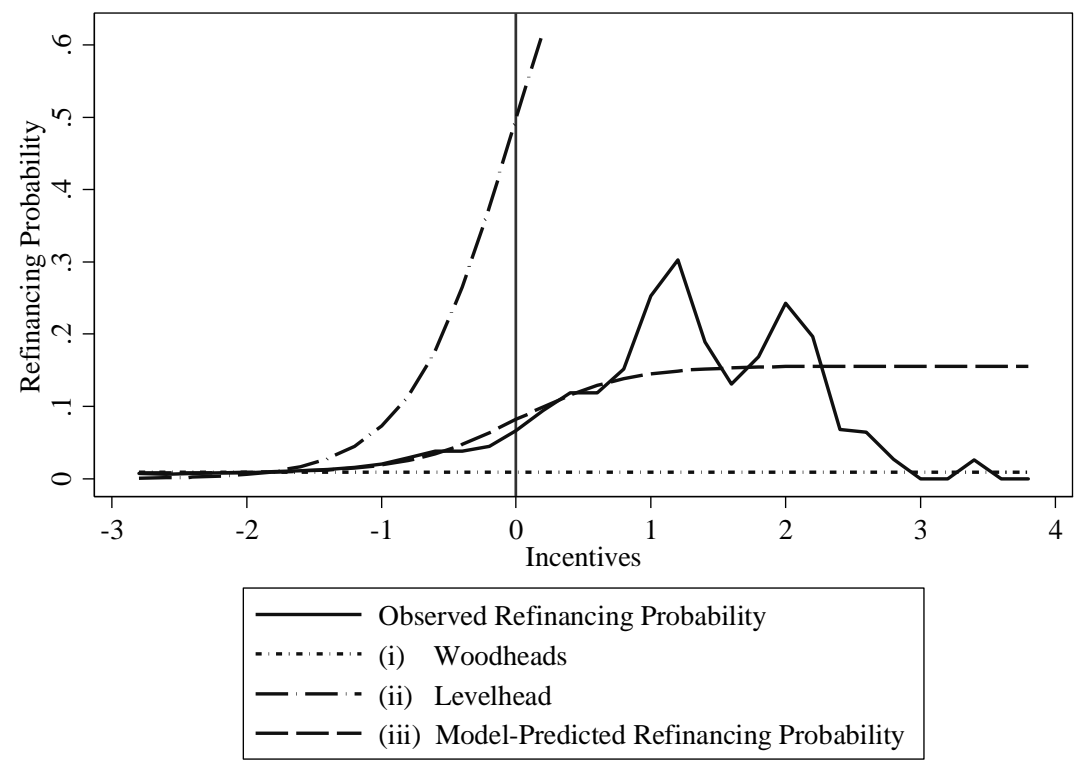

Figure 2: Histogram of Estimated Mortgage Termination Probabilities.

This figure shows our estimates of mortgage termination probabilities. To compute these estimates, we fit a simple probit model to realized mortgage terminations using all households with a single fixed-rate mortgage, conditioning the dummy variable for a termination on household characteristics. We plot the fitted values from this probit model, with a dark dashed line at $10 \%$, which is the Agarwal et al. (2013) suggested "hardwired” value.

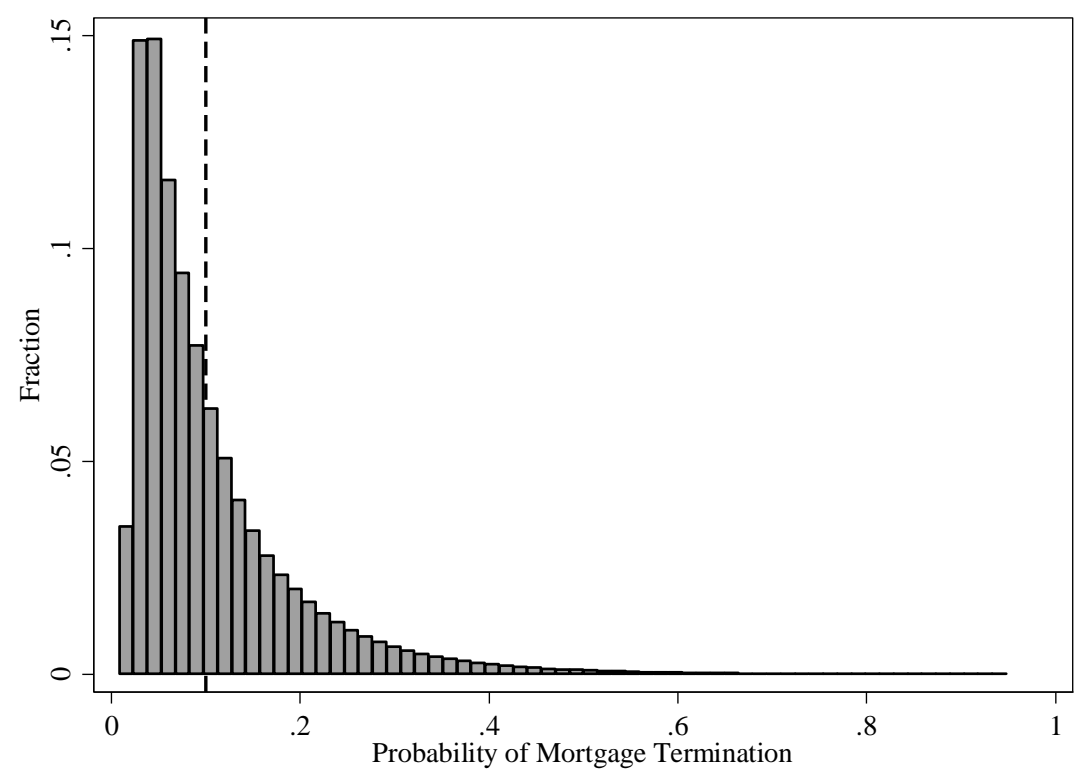


Figure 3: The History of 30-year Danish Mortgage Rates from 2003 to 2013

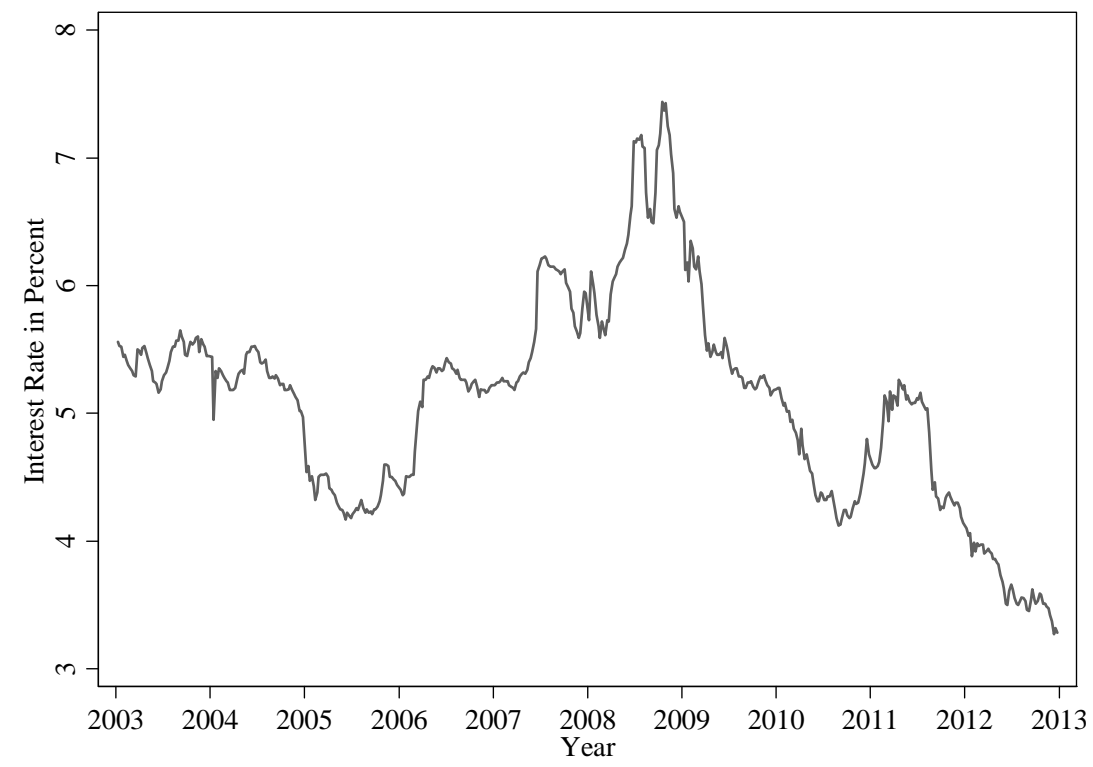

Figure 4: Refinancing Activity by Old Mortgage Coupon Rates

This figure illustrates the history of refinancing activity in our sample of Danish fixed-rate mortgages. In each plot, the bars (left vertical axis) represent the number of refinancing households in the quarter, while the solid line (right vertical axis) shows the history of the mortgage interest rate. The top panel shades each of the bars according to the coupon rate on the old mortgage from which households refinance. The bottom panel shades each of the bars according to the coupon rate on the new mortgage into which households refinance.

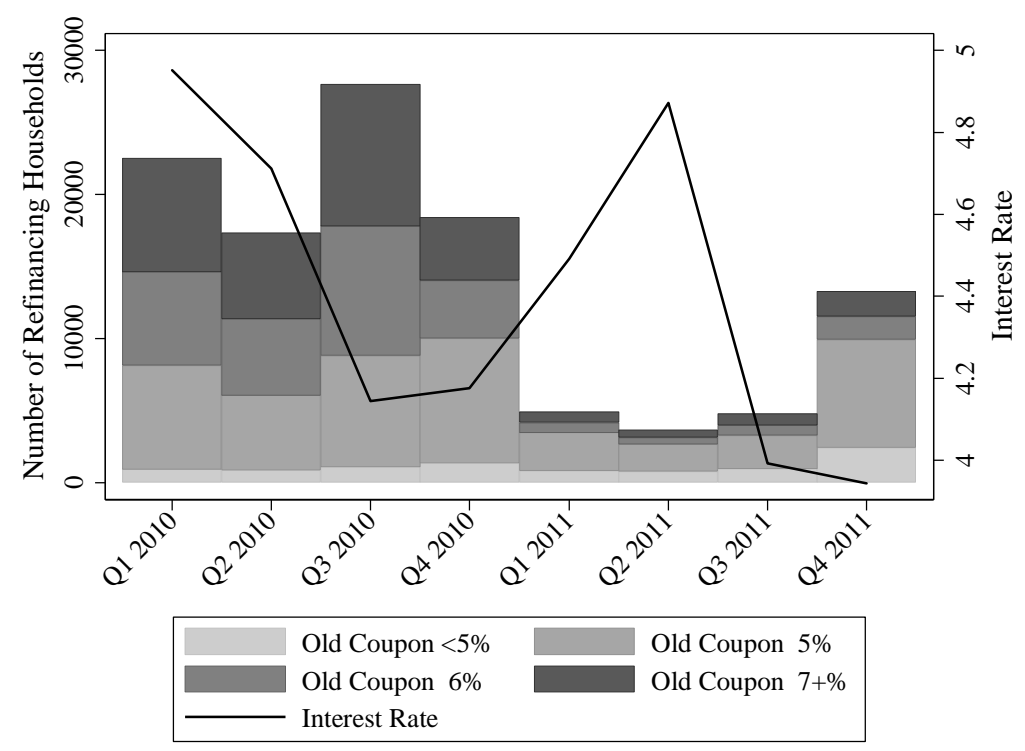


Figure 5: Refinancing and Incentives.

This figure plots the number of household-quarters observations (left vertical axis) and the fraction of total household-quarters refinancing (right vertical axis) at each level of refinancing incentives shown on the horizontal axis. The plot uses 20-basis-point intervals for incentives.

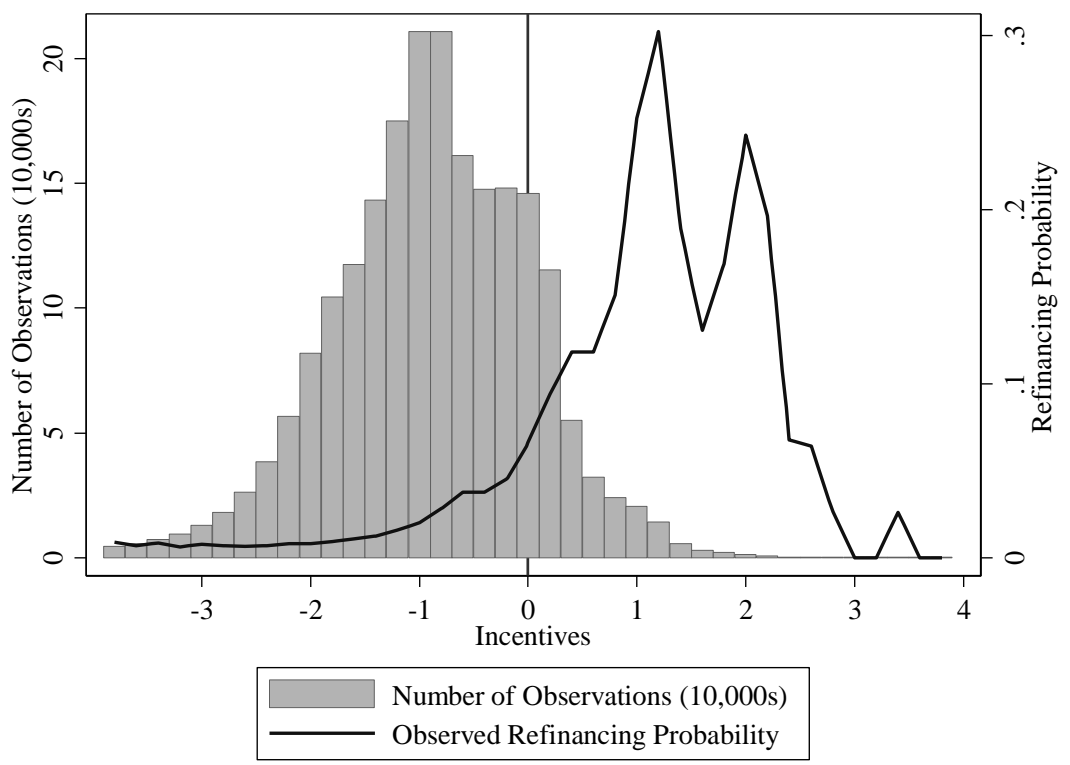

Figure 6: Refinancing probability by Types, and the Fraction of Refinancing.

This figure plots refinancing probabilities from the complete mixture model with levelheads and woodheads estimated in Table 7, as a function of refinancing incentives constructed in various ways. The solid line in the top panel of the figure shows the observed (raw) refinancing probability, the dashed line with long dashes shows the model-predicted refinancing probability, and the dashed line with shorter dashes shows the fraction of households classified as levelheads in each period.

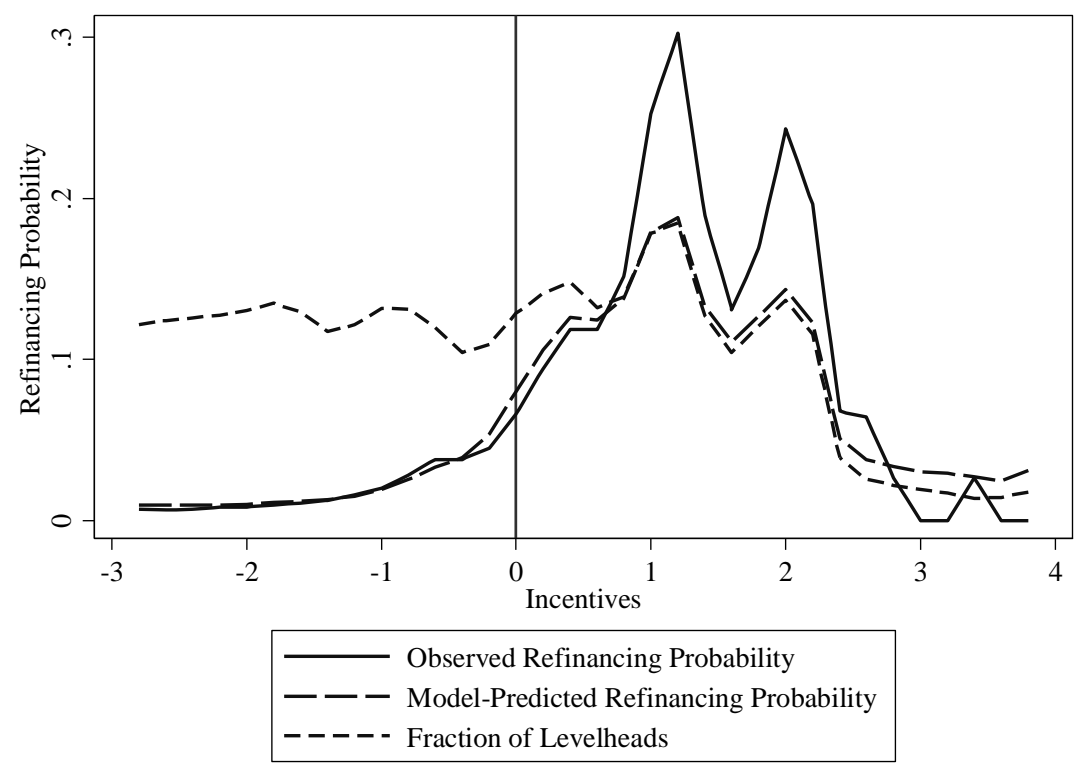




\section{Figure 7: Marginal Effects of Ranked Variables on Levelhead Probability}

This figure shows the marginal change in the probability of being a levelhead as a function of the ranked variables of age, education, income, financial wealth and housing wealth, fixing all other explanatory variables at their unconditional in-sample means, from the complete mixture model with levelheads and woodheads estimated in Table 7.

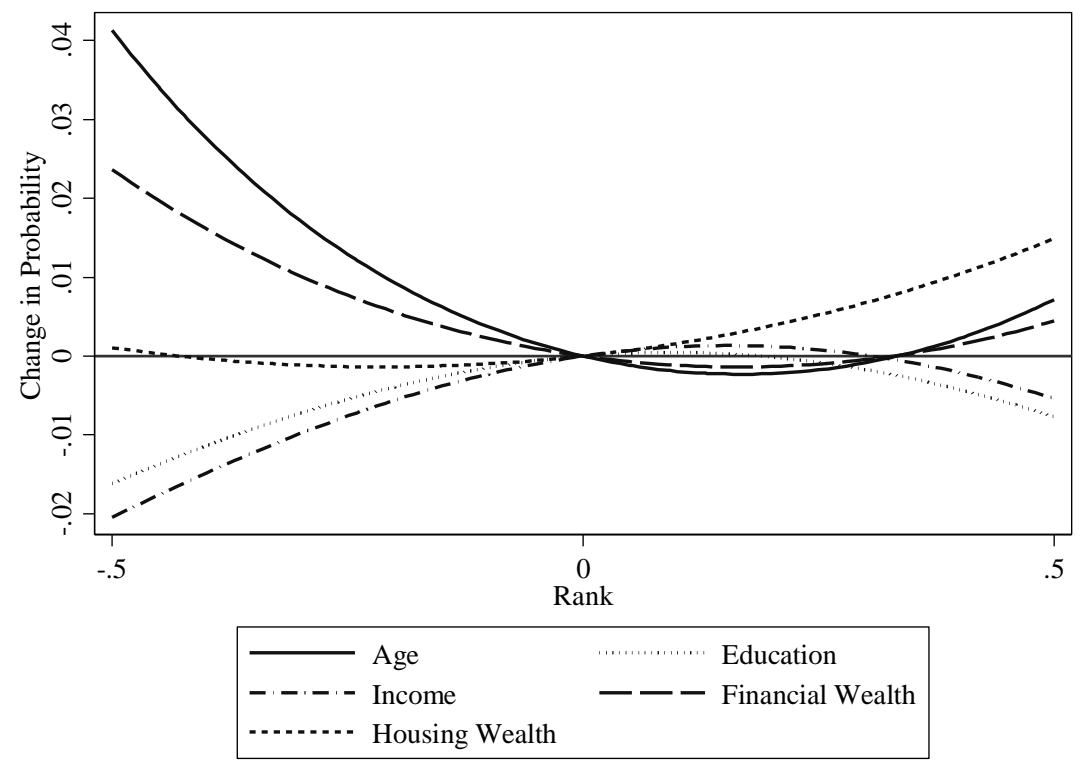

Figure 8: Marginal Effects of Ranked Variables on Woodhead Refinancing Probability

This figure shows the marginal change in the refinancing probability of woodheads as a function of the ranked variables of age, education, income, financial wealth and housing wealth, fixing all other explanatory variables at their unconditional in-sample means, from the complete mixture model with levelheads and woodheads estimated in Table 7.

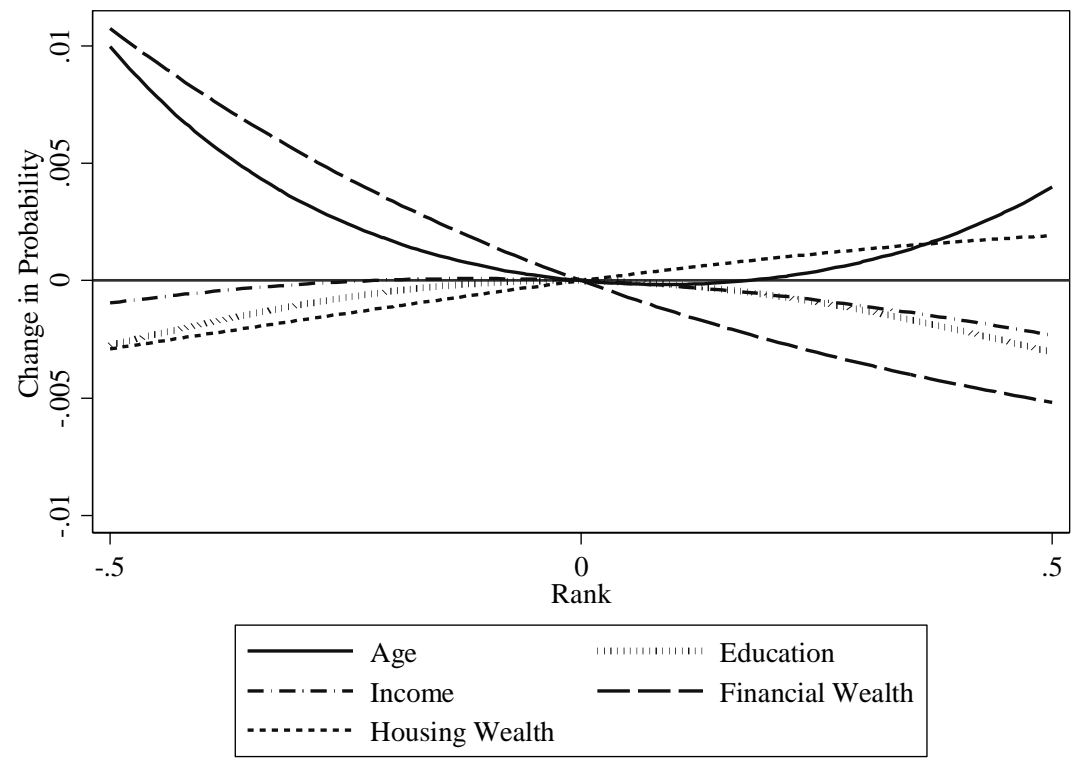




\section{Figure 9: Fitted Refinancing Probability by Issuing Quarter}

This figure plots the predicted refinancing probability of woodheads (y-axis) by issuing quarter (x-axis) using the estimated mixture model in Table 7, predicted at the mean for all other variables than the relevant issuing quarter. The first issuing quarter is issuing quarters within our refinancing period 2009-2011. The fraction of periods with positive incentives for each issuing quarter is plotted as the line and uses the scaled on the right axis.

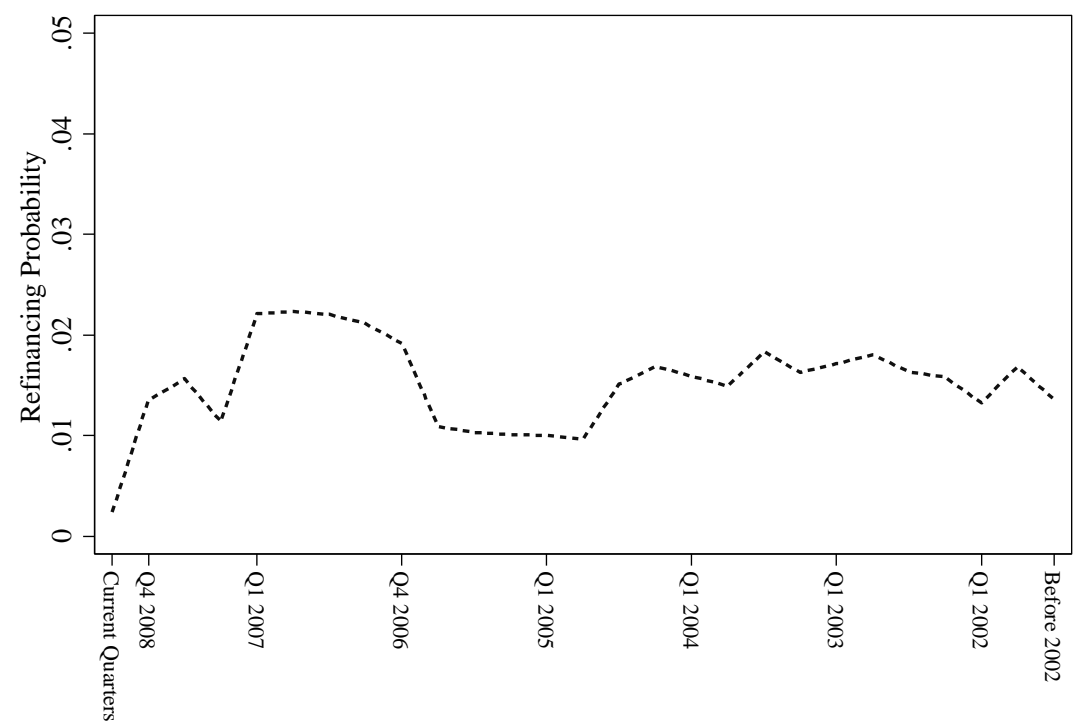

Issuing Quarter

\section{Figure 10: Fitted Refinancing Probability by Issuing Quarter, Heterogeneous Types}

This figure plots the levelhead probability (left y-axis) by issuing quarter (x-axis) using the estimated mixture model in Table 7, predicted at the mean for all other variables than the relevant issuing quarter. The second line plots the fraction of periods with positive incentives using the Agarwal et al. (2013) formula for each issuing quarter and uses the scale on the right axis. The first issuing quarter is issuing quarters within our refinancing period 2009-2011.

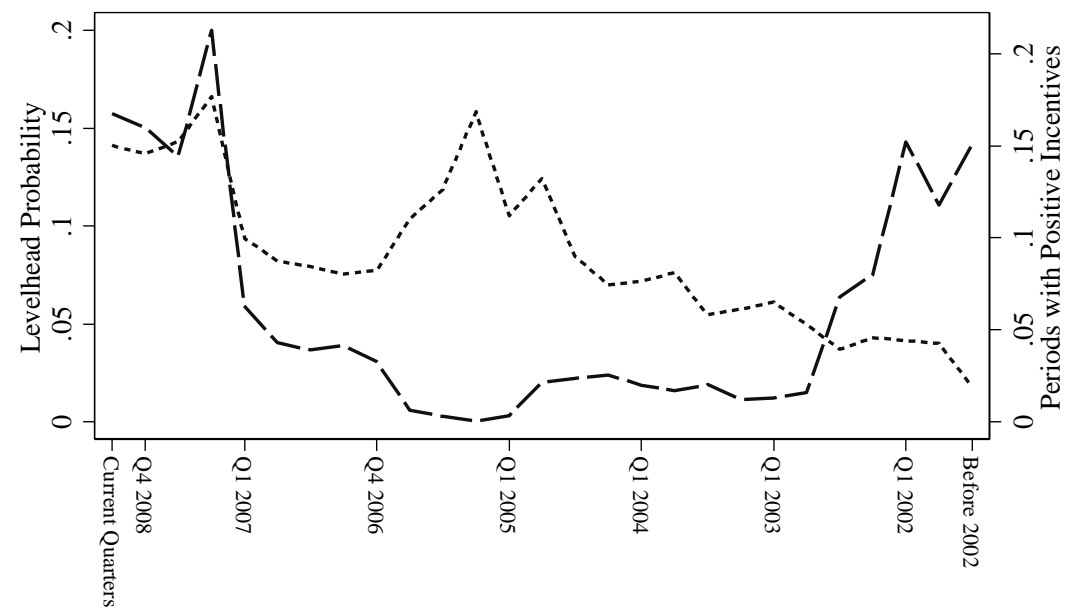

Issuing Quarter

.....-. Levelhead Probability

- - Fraction of Periods with Positive Incentives 